Check for updates

Cite this: Mater. Adv., 2022, 3, 707

Received 28th August 2021 Accepted 20th November 2021

DOI: 10.1039/d1ma00771h

rsc.li/materials-advances

\title{
Advances in porous organic polymers: syntheses, structures, and diverse applications
}

\author{
Mohamed Gamal Mohamed, (D) *ab Ahmed. F. M. EL-Mahdy, (D) a \\ Mohammed G. Kotp ${ }^{a}$ and Shiao-Wei Kuo iD *ac
}

\begin{abstract}
Porous organic polymers (POPs) are organic macromolecules that are considered emerging materials because of their high specific surface areas, tunable porosities, low densities, high chemical and thermal stabilities, variable compositions, convenient post-functionalization, extended $\pi$-conjugations, and their high contents of carbon, nitrogen, oxygen, and other non-metallic atoms. POPs have been classified into four types: covalent triazine frameworks (CTFs), hypercrosslinked polymers (HCPs), covalent organic frameworks (COFs), and conjugated microporous polymers (CMPs). These materials have potential applications in, for example, gas capture/separation, energy storage, $\mathrm{H}_{2}$ production from water, photocatalysis, chemical sensing, perovskite solar cells, water treatment, optical devices, and biomedicine. In this review, we provide an overview of recent reports describing the preparation and various applications of POPs.
\end{abstract}

\section{Introduction}

Porous structures have existed in nature for a very long time in, for example, charcoal, biological tissues, and rocks. ${ }^{1}$ The word "porous" is usually used to describe a material featuring interconnected permanent voids that allow the passage of gases or liquids. ${ }^{1}$ Porous materials are applied in many technological and scientific fields, with a huge number of new advanced porous materials having been developed during the last two decades. ${ }^{2-14}$ Based on the IUPAC classification, porous materials can be divided, based on their pore diameters, into microporous $(<2 \mathrm{~nm})$, mesoporous ( $>2 \mathrm{~nm}$ and $<50 \mathrm{~nm})$, and macroporous $(>50 \mathrm{~nm})$ materials. ${ }^{15-22}$ Various porous materials have been constructed from metal-organic frameworks (MOFs) and porous organic polymers (POPs). ${ }^{1,23-28}$ MOFs are typically crystalline porous materials or porous coordination polymers obtained through the formation of coordinate bonds between organic ligands and clusters or metal ions to form voids within the framework structure, thereby resulting in porosity. ${ }^{23-25}$ In the past two decades, many groups have prepared various subclasses of POP frameworks, including porous aromatic frameworks (PAFs), covalent triazine frameworks (CTFs), covalent organic frameworks (COFs), polymers of intrinsic microporosity (PIMs), hypercrosslinked

\footnotetext{
${ }^{a}$ Department of Materials and Optoelectronic Science, Center for Functional Polymers and Supramoleuclar Materials and Center of Crystal Research, National Sun Yat-Sen University, Kaohsiung 804, Taiwan.

E-mail: mgamal.eldin34@gmail.com,kuosw@faculty.nsysu.edu.tw

${ }^{b}$ Chemistry Department, Faculty of Science, Assiut University, Assiut, 71516, Egypt

${ }^{c}$ Department of Medicinal and Applied Chemistry, Kaohsiung Medical University,

Kaohsiung 807, Taiwan
}

polymers (HCPs), and conjugated microporous polymers (CMPs) (Fig. 1). ${ }^{1,29-33}$ The preparation of each kind of POP generally occurs through network reactions. ${ }^{1}$ All POPs are amorphous materialsexcept for a small number of CTFs and COFs that are crystalline materials with ordered structures prepared under thermodynamic control. ${ }^{1}$ Like nanoporous materials, POPs have many potential applications because of their high surface areas and uniform pore sizes, with large numbers of channels and active sites available for chemical reactions. ${ }^{3,34-37}$ Accordingly, POPs have attracted attention for their use in, for example, the degradation of organic pollutants, energy storage, photocatalysis, $\mathrm{H}_{2}$ evolution, light harvesting, photovoltaics, luminescence, gas adsorption and separation, chemical sensing, and drug loading and delivery. ${ }^{38-54}$ Various morphologies of POPs, including nanotubes, nanospheres, and nanosheets, can be controlled by varying the synthetic method, the monomer structure, or the reaction conditions. $^{45,48,55}$ Furthermore, the surface areas of POPs, typically in the range $100-1000 \mathrm{~m}^{2} \mathrm{~g}^{-1}$, are higher than those of MOFs and porous carbons. ${ }^{3}$ In 2007 , Yaghi et al. prepared a 3D-COF-103 possessing a high Brunauer-Emmett-Teller (BET) surface area of $4210 \mathrm{~m}^{2} \mathrm{~g}^{-1} \cdot{ }^{56}$ Ben et al. used the Yamamoto reaction to prepare a PAF (PAF-1) exhibiting a high specific area $\left(4210 \mathrm{~m}^{2} \mathrm{~g}^{-1}\right) .{ }^{57}$ The insolubility of POPs in organic solvents, due to their rigid chemical bonds and high degrees of polymerization, can simplify the separation and recycling of POPs. ${ }^{3}$ In this review, we provide an overview of recent reports describing the preparation of POPs (including CTFs, COFs, HCPs, and CMPs) and their applications in photocatalytic water splitting for $\mathrm{H}_{2}$ evolution, gas capture and separation, chemosensing, the removal of dyes and metals, organic synthesis, and energy storage. 


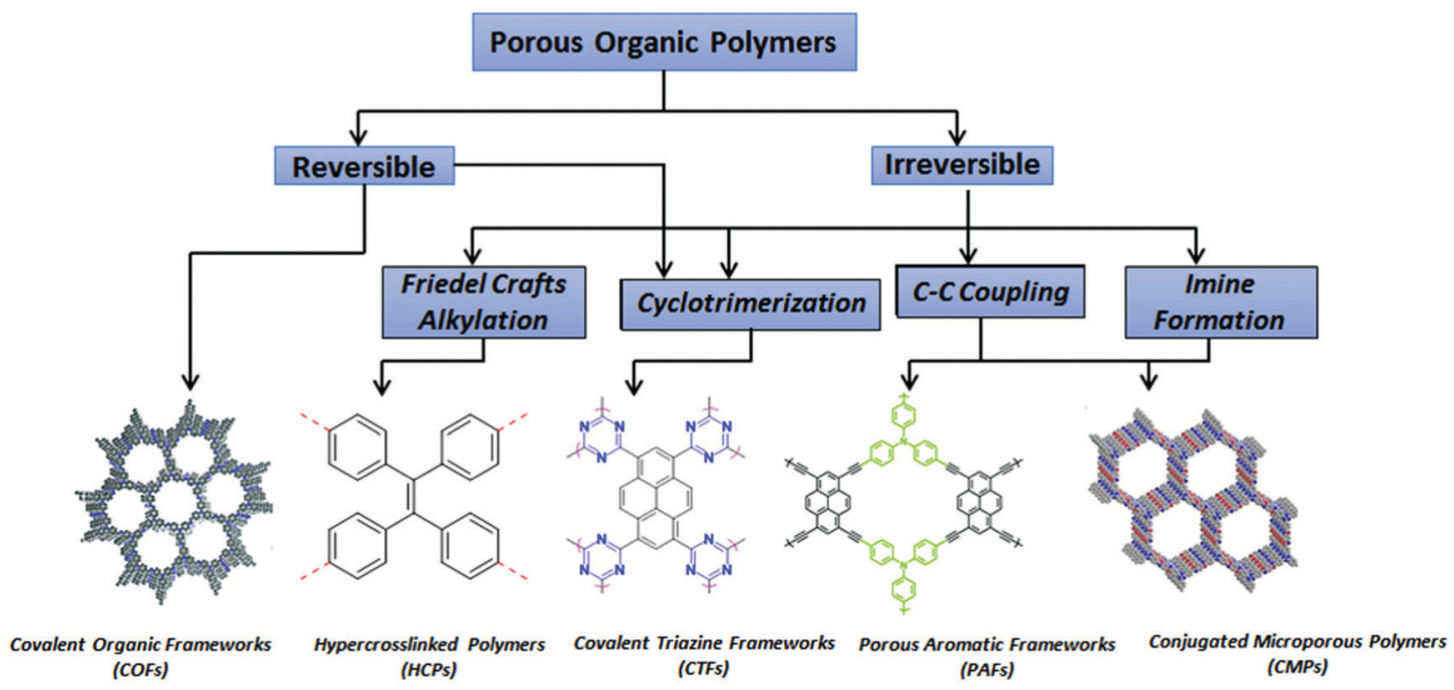

Fig. 1 Types of porous organic polymer frameworks and their coupling formation reactions.

\section{Preparation of POPs}

In this section, we discuss progress in the synthetic methodologies that are widely used for the preparation four kinds of POPs: HCPs, CTFs, CMPs, and COFs.

\subsection{Preparation of HCPs}

HCPs are porous polymers that have attracted much attention for their extended conjugation; tunable porosities; high surface areas; high mechanical, chemical, and hydrothermal stabilities; variety of potential synthetic methods; and facile postfunctionalization after HCP formation. ${ }^{58-63}$ Many methods have been used to determine the chemical structures, thermal stabilities, morphologies, and textural characteristics (e.g., pore size diameters and surface areas) of HCPs, including Fourier transform infrared (FTIR) spectroscopy, elemental analysis, solid state nuclear magnetic resonance (NMR) spectroscopy, transmission electron microscopy (TEM), optical microscopy, field emission scanning electron microscopy (SEM), $\mathrm{N}_{2}$ adsorption isotherms, and thermogravimetric analysis (TGA). ${ }^{5-63}$ Davankov and Tsyurupa were the first to generate threedimensional (3D) network structures of linear polystyrene (PS) with high surface areas (up to $2000 \mathrm{~m}^{2} \mathrm{~g}^{-1}$ ) as the first HCP material, through post-crosslinking of a PS precursor in the swollen state. ${ }^{64}$ The formation HCPs can be achieved through acid-catalyzed Friedel-Crafts reactions involving a Lewis acid catalyst, a reaction solvent, and arene-based nucleophilic and electrophilic species. ${ }^{65}$ To avoid products forming through side reactions during the knitting step, the reactions are performed under $\mathrm{Ar}$ and $\mathrm{N}_{2}$ atmospheres to afford pure HCPs as solid materials. ${ }^{65}$ The incorporation of metal species into HCPs can be performed through post-modification-by introducing a metal salt or complex-or by using a metal complex as a comonomer or monomer during the knitting reaction (Fig. 2). ${ }^{65}$ HCP materials have been employed in many applications, including energy storage; (supercapacitor devices, and lithium, sodium, and potassium batteries); chemical sensing; heterogeneous catalysis; optoelectronic devices; drug delivery; gas capture and separation; and chromatographic separation. ${ }^{58-65}$

\subsection{Preparation of CTFs}

CTFs are partially crystalline, amorphous porous materials possessing conjugated and layered structures. ${ }^{66}$ Thomas and co-workers were the first to report examples of CTF materials containing aromatic rings and triazine moieties in the core. ${ }^{6}$ CTFs have attracted much attention for their potential applications in, for example, $\mathrm{CO}_{2}$ reduction, pollutant degradation, organosynthesis, water splitting, $\mathrm{H}_{2} \mathrm{O}_{2}$ and $\mathrm{H}_{2}$ production, and organic semiconductor devices. ${ }^{67-72}$ Several approaches have been used for the preparation of CTFs, including cyclotrimerization of nitrile groups through direct or indirect methods in the presence of molten $\mathrm{ZnCl}_{2}$ at $400{ }^{\circ} \mathrm{C}$; superacid-catalyzed trimerization; Suzuki cross-coupling; Ni-catalyzed Yamamoto coupling; and $\mathrm{P}_{2} \mathrm{O}_{5}$ catalysis at $400{ }^{\circ} \mathrm{C}$ (Fig. 3). ${ }^{66}$ The preparation of CTFs with highly crystalline structures requires the selection of monomers with planar characteristics; the use of nonplanar monomers leads to the formation amorphous or semicrystalline CTFs. ${ }^{73-76}$ To date, only a few crystalline CTFs have been reported. For example, Tang et al. found that the degree of crystallinity of CTFs and the formation of uniform layered structures increased upon increasing the microwave power from 20 to $100 \mathrm{~W} .^{77}$ Interestingly, $\mathrm{Xu}$ et al. prepared a two-dimensional (2D) CTF with a well stacked structure within $10 \mathrm{~min}$ at $25{ }^{\circ} \mathrm{C}$ through a $\mathrm{TfOH}$-catalyzed interfacial reaction, with simple purification procedures applied after the trimerization reactions (Fig. 4).$^{78}$ They found that the crystalline CTFs formed using this approach were AB-staggered; in contrast, mostly crystalline CTFs exhibiting the AA stacking mode were obtained when using the ionothermal method.

\subsection{Preparation of CMPs}

CMPs are microporous organic polymers that are emerging materials because of their permanent building blocks; huge 
The first knitting model

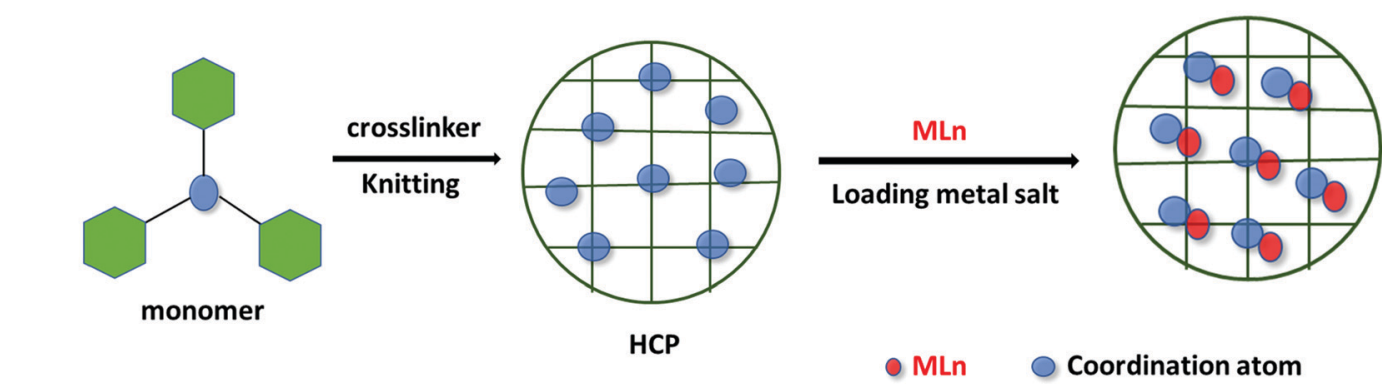

The second knitting model

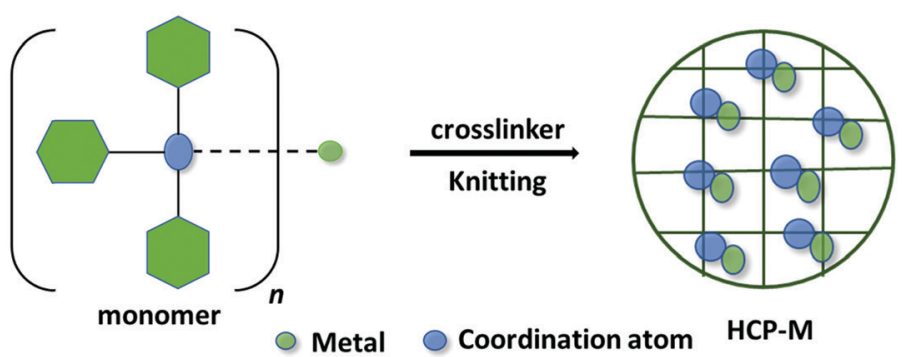

Fig. 2 Schematic cartoon for incorporating metal species into HCP frameworks via two different knitting models. Reproduced from ref. 65 with permission from Wiley- $\mathrm{VCH}$.

(a)<smiles>N#Cc1ccc(CC2CC2)cc1</smiles>

(b)<smiles>CC1(C(C)(C)c2ccc(C(N)=O)cc2)CC1</smiles>

(c)<smiles>Cc1ccc(C#N)cc1</smiles>

(f)<smiles></smiles><smiles>Cc1ncnc(-c2ccc(-c3ncnc(-c4ccc(-c5ncnc(C)n5)cc4)n3)cc2)n1</smiles><smiles>Cc1nc(-c2ccc(C(=N)N)cc2)nc(-c2ccc(-c3nc(C)nc(-c4ccc(-c5nc(C)nc(-c6ccc(C(=N)N)cc6)n5)cc4)n3)cc2)n1</smiles>

$\mathrm{Cs}_{2} \mathrm{CO}_{3}$

(d)<smiles>Nc1ccc(C=[NH2+])cc1</smiles><smiles>NCc1ccc(C=O)cc1C=O</smiles>

(e)<smiles></smiles>

Fig. 3 Formation of CTFs via direct or indirect approaches. Reproduced from ref. 66 with permission from American Chemical Society. 

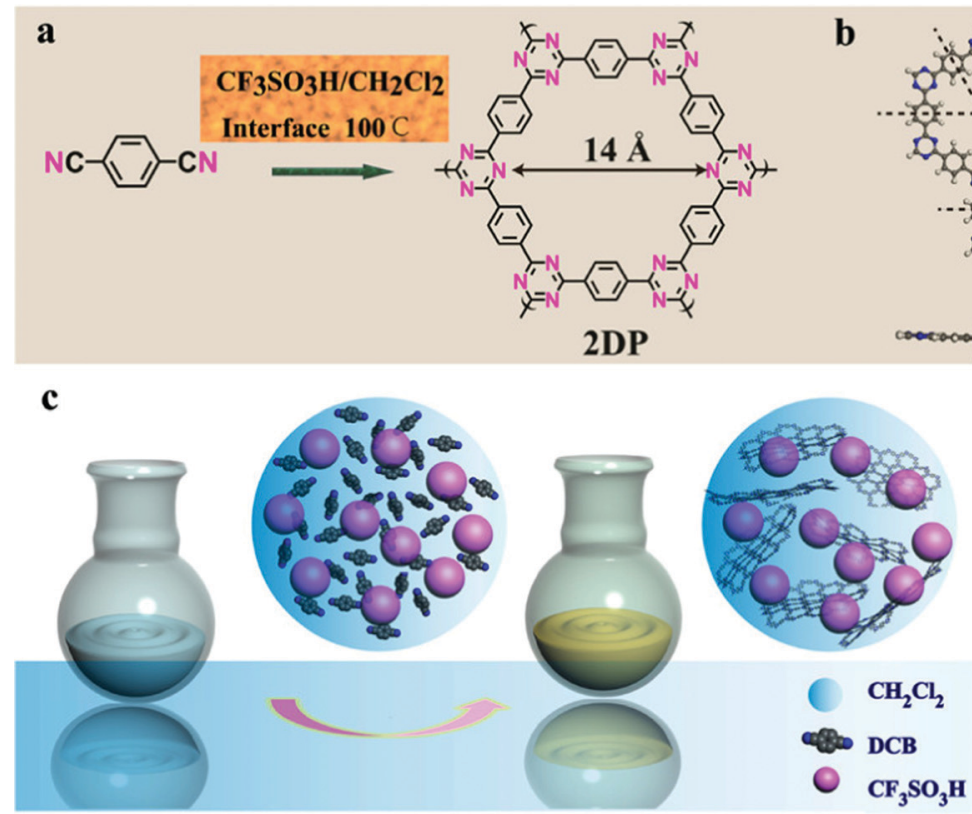

b

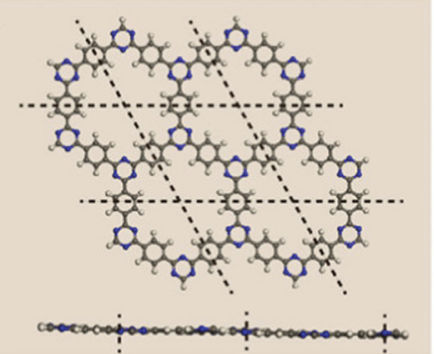

d

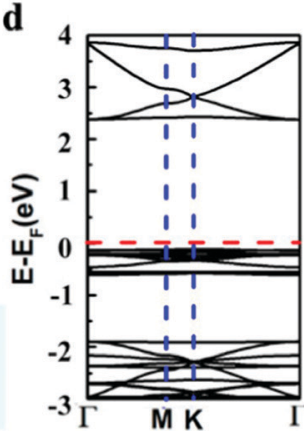

Fig. 4 (a) and (b) Synthesis of 2D-CTFs through polymerization at $\mathrm{CH}_{2} \mathrm{Cl}_{2} / \mathrm{CF}_{3} \mathrm{SO}_{3} \mathrm{H}$ interfaces, (b) and (d) represent the atomic structure and DFT band structure of the 2D-CTF. Reproduced from ref. 78 with permission from American Chemical Society.

surface areas; structural adjustability, diversity, and modularity; expanded degrees of conjugation; and excellent physiochemical stabilities. ${ }^{79-82}$ Accordingly, CMPs have been used widely as materials for photovoltaic devices, light-harvesting, photocatalysis, adsorbents, luminescent materials, and clean energy applications (e.g., supercapacitors, $\mathrm{H}_{2}$ storage, photocatalytic cells, metal-ion rechargeable batteries, $\mathrm{CO}_{2}$ capture and conversion, and fuel cells). ${ }^{79-82}$ The interesting properties of CMPs arise from (i) their expanded conjugated structures along the polymer chains (significantly enhancing their chemical and physiochemical stabilities) and (ii) their high surface areas and highly crosslinked polymeric network structures (improving their electrochemical activities, cycle stabilities, and kinetics and preventing the active material from dissolution into organic electrolytes). ${ }^{79-84}$ The approaches used most widely for the preparation of CMPs include phenazine ring fusion, electropolymerization, alkyne metathesis, Schiff base formation, and Yamamoto, Heck, Sonogashira-Hagihara, Buchwald-Hartwig, and Suzuki-Miyaura cross-couplings. These methods allow good selectivities, a range of different of substrates, suitable reaction conditions, simple post-synthetic modifications, and the high-yield production of CMPs with high specific surface areas.

\subsection{Preparation of COFs}

COFs are important emerging materials with potential applications in a wide range of fields, including optics, gas capture, lithium-sulfur batteries, electrocatalysis, metal adsorption, light harvesting, and sensing; they are easy to prepare with high surface areas and total pore volumes, moderate physical and chemical properties, and homogeneous micropores. ${ }^{85-92}$ COFs have been formed with 2D and 3D network structures comprising backbones containing carbon (C) and hydrogen $(\mathrm{H})$ atoms as well as other elements, including oxygen (O), boron (B), sulfur (S), and nitrogen (N) atoms. Various topologies of 2D and 3D COFs can be induced by varying the geometries and dimensions of their building blocks (Fig. 5). ${ }^{93}$ Compared with other porous polymeric materials, the ability to predict the skeleton structures of COFs is unique. The many synthetic techniques available for the preparation of COFs include sonochemical methods, interfacial synthesis, ionothermal synthesis, mechanochemical methods, microwave-assisted synthesis, and solvothermal synthesis. ${ }^{93}$ The fabrication of COF skeletons with particular pore sizes and symmetries depends on the choice of suitable linkers and organic building blocks. The types of linkers that have been used for the preparation of COFs include hydrazone, phenazine, imine, azine, boroxine, imide, and triazine units (Fig. 6). ${ }^{93}$ 2D COF frameworks can have nine different topologies: hexagonal layer (hxl), kgd, tth, mtf, bex, kagome (kgm), hexagonal tungsten bronze (htb), square lattice (sql), and hcb (Fig. 7). ${ }^{94}$ Feng and co-workers prepared a 3D anionic CDCOF (rra net) containing trinodal secondary building units through the condensation reaction of $\gamma$-CD with $\mathrm{B}(\mathrm{OMe})_{3}$ in the presence of $\mathrm{LiOH}$ under microwave conditions. ${ }^{95}$ In addition, Yaghi et al. obtained a COF-based tth topology when combining square-planar, hexagonal, and triangular building blocks and observed th topology tiling. ${ }^{96}$

\section{Potential applications of POPs}

\section{1. $\mathrm{CO}_{2}$ capture}

POPs are ideal candidates for capturing $\mathrm{CO}_{2}$ gas in a green and environmentally friendly manner. Very recently, the Tan group prepared two novel inorganic-organic crosslinked polymers (HCP-PN-1, and HCP-PN-2) based on phosphazene moieties through Friedel-Crafts alkylations for the nucleophilic 


\section{A. 2D COFs}

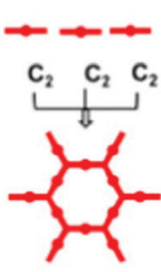

Hexagonal
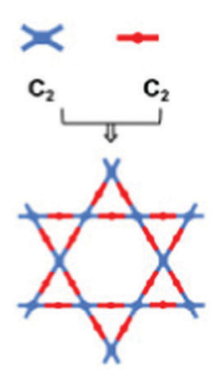

Dual-pore Kagome

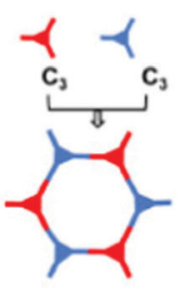

Hexagonal

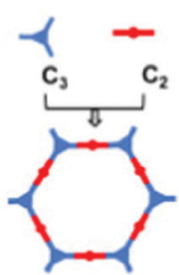

Hexagonal

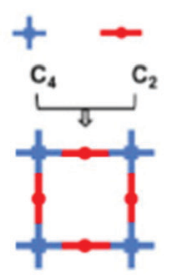

Tetragonal

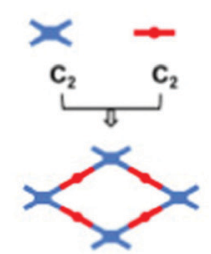

Single-pore rhombic

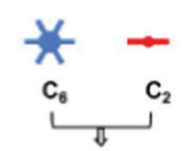

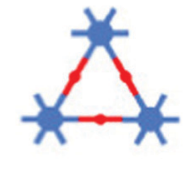

Trigonal

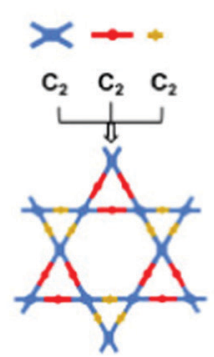

Triple-pore Kagome

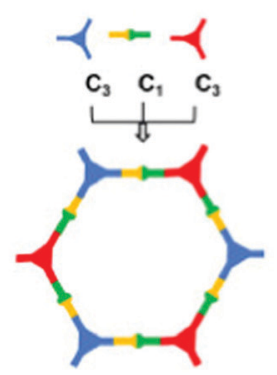

Hexagonal

\section{B. 3D COFs}
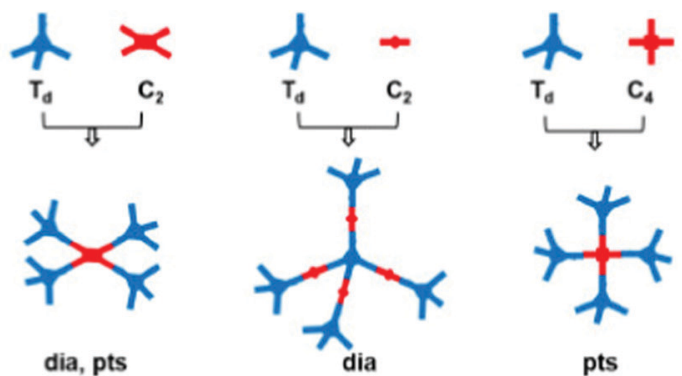

pts
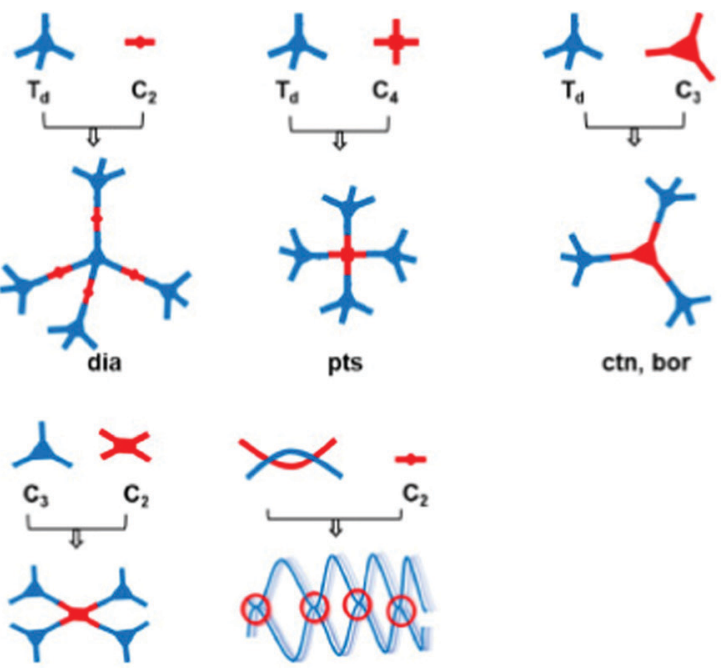

ffc

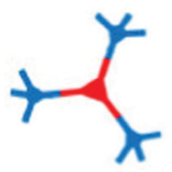

ctn, bor
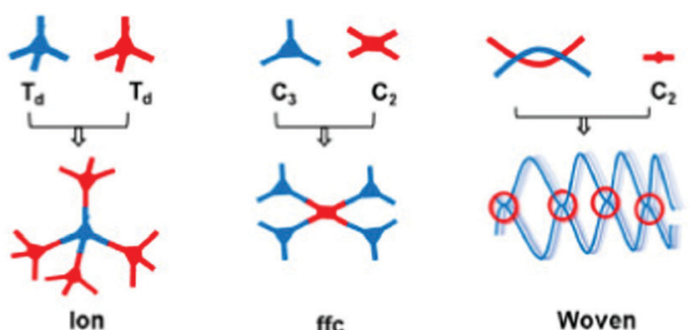

Woven

Fig. 5 Topology diagrams representing a general basis for COF design and the construction of (A) 2D COFs and (B) 3D COFs. ${ }^{93}$ Reproduced from ref. 93 with permission from Elsevier.

substitution of hexachlorotriphosphazene with 2-naphthol (PN-Nap-1 and PN-Nap-2) to give nitrogen- and phosphorusenriched HCPs (Fig. 8). ${ }^{97}$ Interestingly, these HCPs had hierarchical pore structures and high surface areas (based on BET measurements) that led to high degrees of $\mathrm{CO}_{2}$ adsorption (HCP-PN-1: $72 \mathrm{mg} \mathrm{g}^{-1}$; HCP-PN-2: $57 \mathrm{mg} \mathrm{g}^{-1}$; at $273 \mathrm{~K}$ ). Li et al. prepared MOP-PZ containing $\mathrm{N}=\mathrm{C}$ and $\mathrm{NH}$ groups through a Scholl reaction of 3,5-diphenyl- $1 H$-pyrazole in the presence of $\mathrm{AlCl}_{3}$ in $\mathrm{CHCl}_{3}$ as the solvent. They prepared the hybrid material MOP-PZ-Ag by embedding silver nanoparticles (NPs) into MOP-PZ, and found that MOP-PZ-Ag functioned as a heterogeneous catalyst for the production of propiolic acid through the carboxylation of some terminal alkynes; this stable hybrid material also displayed an excellent degree of $\mathrm{CO}_{2}$ adsorption (183.7 $\left.\mathrm{mg} \mathrm{g}^{-1}\right) .{ }^{98}$ Wang and co-workers prepared nitrogen-enriched microporous polymers containing various contents of amino groups through condensation reactions of melamine with formohydrazide, formamide, $\mathrm{N}, \mathrm{N}$-dimethylformamide (DMF), and $N$-methylformamide. These four polymers possessed pore diameters of $0.52-1.10 \mathrm{~nm}$ and specific surface areas of $612-748 \mathrm{~m}^{2} \mathrm{~g}^{-1}$, with the BET method, and SEM, and TEM analysis revealing that they were agglomerates of tiny particles with an irregular shape and porous structures; the four polymers provided $\mathrm{CO}_{2}$ uptakes of up to $103 \mathrm{mg} \mathrm{g}^{-1}$ at $273 \mathrm{~K} .{ }^{99}$ Liang et al. prepared four kinds of CMPs and used a post-knitting approach to improve their porosities, affording 
(a)

(b)

(c)

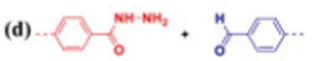

(e)

(f)

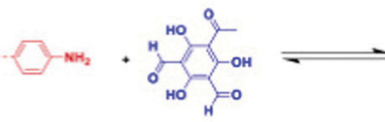

(g)

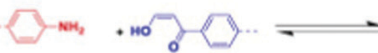

(h)
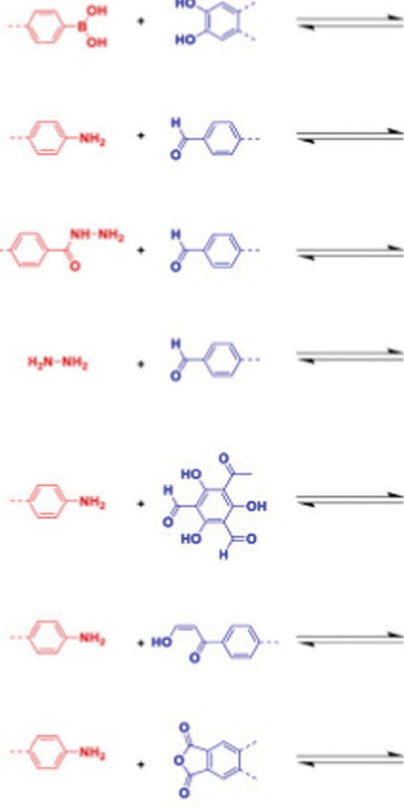
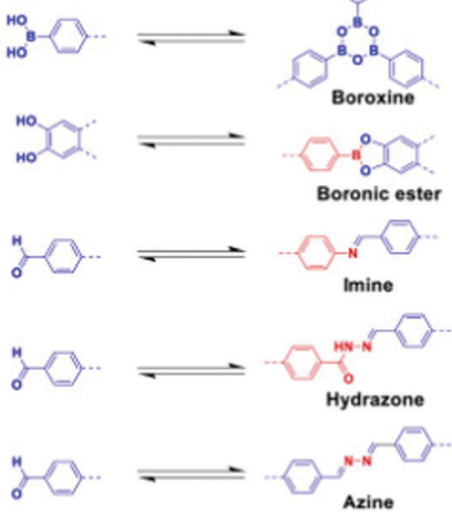

Azine

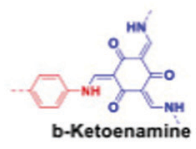

b-Ketoenamine
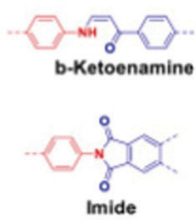

(i)
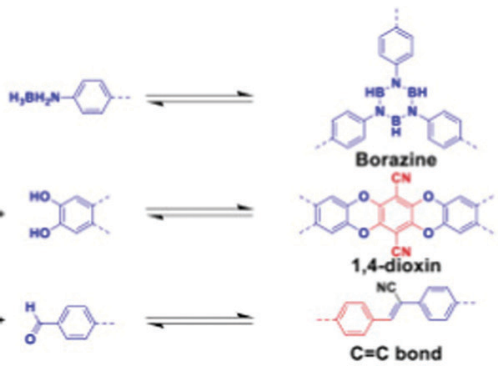

(
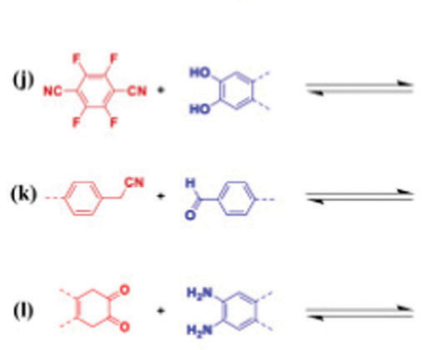

(m)
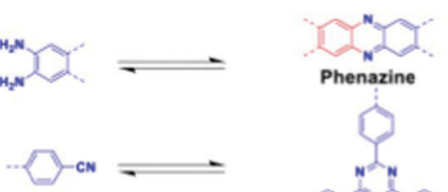

(n)
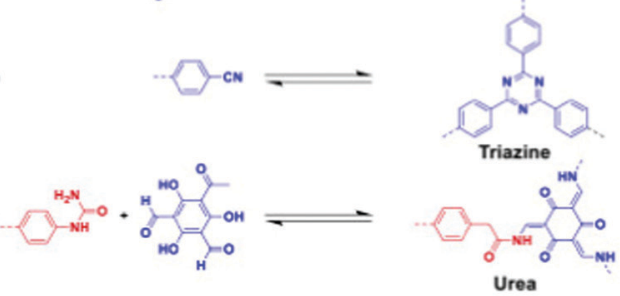

(o)
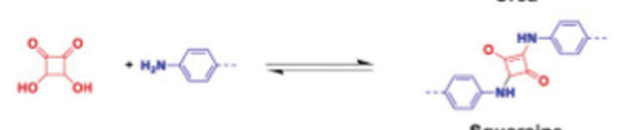

(p)
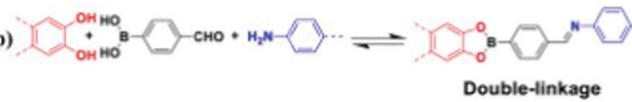

Fig. 6 Various linkages for COF formation. Reproduced from ref. 93 with permission from Elsevier.

eight CMP-based HCPs (KCMPs) (Fig. 9). ${ }^{100}$ These KCMPs had high specific surface areas (up to $2267 \mathrm{~m}^{2} \mathrm{~g}^{-1}$ ), high pore volumes (up to $3.27 \mathrm{~cm}^{3} \mathrm{~g}^{-1}$ ), and excellent degrees of $\mathrm{CO}_{2}$ uptake (up to $175.12 \mathrm{mg} \mathrm{g}^{-1}$ at $273 \mathrm{~K}$ ). Das et al. prepared two kinds of CTFs based on 1,2,3-triazolo units; their Tz-CTF polymeric frameworks exhibited excellent $\mathrm{CO}_{2}$ uptake capacities, with a high surface area, chemical and thermal stabilities, agglomerated tiny particles, and regular porous structures, based on SEM and TEM imaging. ${ }^{101}$ Our group also prepared two bicarbazole-based COFs (Cz-BD, and Cz-DHBD) through Schiff-base condensations of $\mathrm{Cz}-4 \mathrm{CHO}$ (as the $C_{2}$-symmetric knot) with BD and DHBD. ${ }^{102}$ These Cz-BD and Cz-DHBD COFs possessed high surface areas (up to 2111 and $992.2 \mathrm{~m}^{2} \mathrm{~g}^{-1}$, respectively) as well as thermal stability up to $507{ }^{\circ} \mathrm{C}$. The Cz-DHBD COF featured a kagome structure, due to intramolecular $\mathrm{OH} \cdots \mathrm{N}$ hydrogen bonding, that increased the steric bulk hinderance and decreased the nucleophilicity of the imino nitrogen atoms, thereby decreasing its ability to capture $\mathrm{CO}_{2}$ (110.59 $\mathrm{mg} \mathrm{g}^{-1}$ ) relative to that of the Cz-BD COF $\left(125.95 \mathrm{mg} \mathrm{g}^{-1}\right)$. In addition, we have prepared hollow microspherical and microtubular carbazole-based COFs through condensations of Car- $3 \mathrm{NH}_{2}$ and the triformyl linkers TPA-3CHO, TPP-3CHO, and TPT-3CHO with various degrees of planarity, obtaining high surface areas of 1334,743 , and $721 \mathrm{~m}^{2} \mathrm{~g}^{-1}$, respectively. Due to their high surface areas, these Car-TPA, Car-TPT, and Car-TPP COFs provided high degrees of $\mathrm{CO}_{2}$ capture, with recorded uptake rates of up to 61,42 , and $34 \mathrm{mg} \mathrm{g}^{-1}$, respectively, at $298 \mathrm{~K}$. Although Car-TPT and Car-TPP had similar surface areas, the former provided a higher
$\mathrm{CO}_{2}$ capture rate because of the higher nitrogen content of the triazine units in the Car-TPT COF. ${ }^{103}$ The effect of the nitrogen content on the $\mathrm{CO}_{2}$ capture ability of COFs was also observed in six 2D COFs displaying various planarities, symmetries, and nitrogen contents, synthesized through the condensation reaction of TPA- $3 \mathrm{NH}_{2}$ and TPT- $3 \mathrm{NH}_{2}$ (as triarylamine monomers) with the monomers TPA-3CHO, TPP-3CHO, and 2TPT-3CHO (with various degrees of planarity) (Fig. 10). ${ }^{104}$ Here, TPT- $3 \mathrm{NH}_{2}$ is more planar than TPA-3 $\mathrm{NH}_{2}$, and TPT-3CHO is more planar than TPP-3CHO and TPA-3CHO. The COFs with lower planarity possessed lower surface areas; those with higher nitrogen contents and higher nucleophilicities displayed higher degrees of $\mathrm{CO}_{2}$ capture. As expected, the higher nitrogen contents in the TPT-based COFs provided higher rates of $\mathrm{CO}_{2}$ capture (up to $92.38 \mathrm{mg} \mathrm{g}^{-1}$ at $273 \mathrm{~K}$ for TPT-COF-6), with the greater planarity of their building blocks also enhancing the morphology to favor $\mathrm{CO}_{2}$ capture. ${ }^{104}$ We have also prepared $\beta$-ketoenamine-linked COFs (TFP-TPA, TFP-Car, and TFP-TPP) through solvothermal Schiff-base [3+3] polycondensations of TFP-3OHCHO with three tris(aminophenyl)-presenting derivatives (possessing amino, carbazole, and pyridine units, respectively). ${ }^{105}$ The TFP-TPA, TFP-Car, and TFP-TPP COFs possessed different degrees of planarity and surface areas of 457,362 , and $686 \mathrm{~m}^{2} \mathrm{~g}^{-1}$, respectively. The higher degrees of planarity of the TFP-Car and TFP-TPP COFs resulted in higher thermal stabilities and stronger interactions with $\mathrm{CO}_{2}$ molecules at $273 \mathrm{~K}$ (up to 190 and $200 \mathrm{mg} \mathrm{g}^{-1}$, respectively) relative to those exhibited by the lowerplanarity TPA-Car COF $\left(183 \mathrm{mg} \mathrm{g}^{-1}\right) \cdot{ }^{105}$ Nagai et al. reported four 


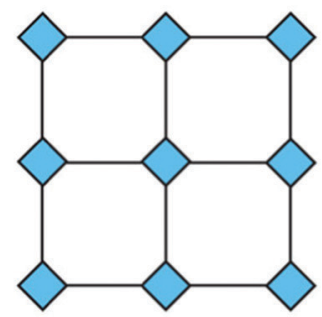

sql-a

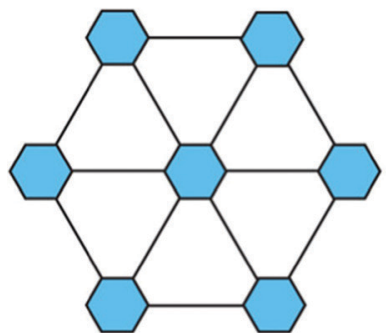

hxl-a

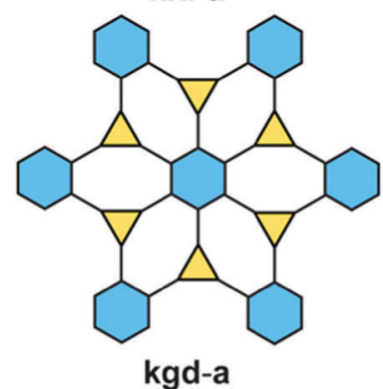

kgd-a

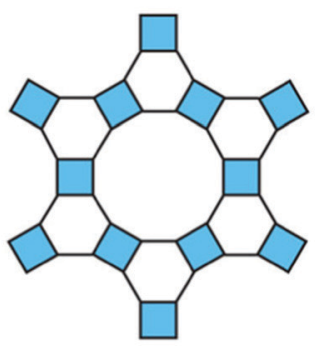

kgm-a = fxt

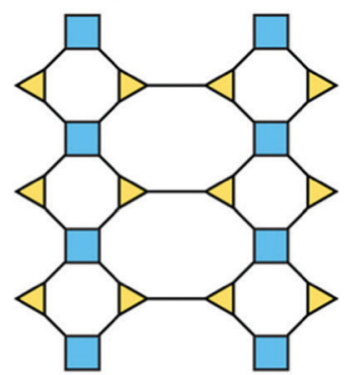

bex-a

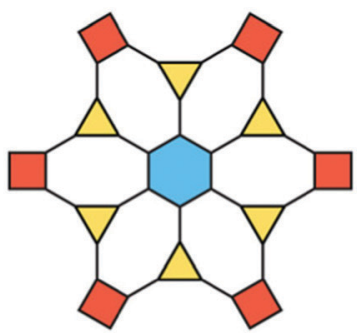

tth-a

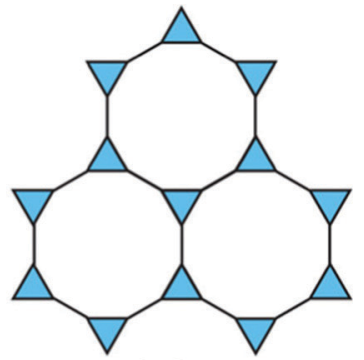

hcb-a

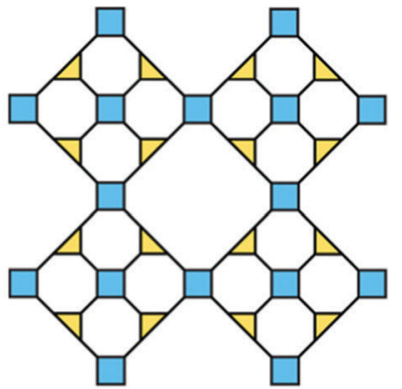

mtf-a

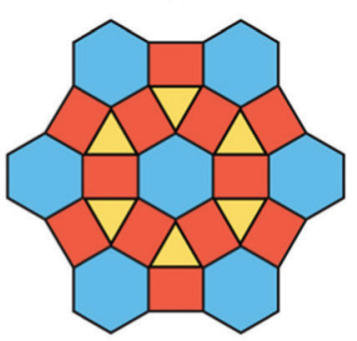

htb-a

Fig. 7 Various topologies in 2D COFs. Reproduced from ref. 94 with permission from American Chemical Society.

types of PI-COF prepared through solvothermal reactions of TAPA and TAPB with PMDA and NTCDA (Fig. 11). ${ }^{106}$ These PI-COF materials had specific surface areas exceeding $500 \mathrm{~m}^{2} \mathrm{~g}^{-1}$ and were applied for $\mathrm{CO}_{2}$ uptake. We have used Schiff base formation, reduction, and Mannich and Sonogashira-Hagihara couplings to prepare two new CMPs (TPE-TPE-BZ, and Py-TPEBZ) featuring benzoxazine-linked tetraphenylethylene and pyrene units (Fig. 12) ${ }^{107}$ Upon thermal treatment, the benzoxazine units in the backbones of the TPE-TPE-BZ and Py-TPE-BZ CMPs underwent ring opening polymerizations to form new materials displaying high performance for $\mathrm{CO}_{2}$ uptake, due to the presence of phenolic $\mathrm{OH}$ and Mannich bridges capable of hydrogen bonding with $\mathrm{CO}_{2}$ molecules.

\subsection{Dyes and iodine adsorption}

$\mathrm{Yu}$ et al. prepared four HCP materials (BCB, Py, CCBCB, and CCPy-CMP) based on perylene, bicarbazole, and triazine units (Fig. 13). ${ }^{108}$ According to BET analyses, the surface areas of BCB, Py, CCBCB and CCPy-CMP were 545, 624, 220, and $20 \mathrm{~m}^{2} \mathrm{~g}^{-1}$, respectively; their surface morphologies featured nanotubes, graphitic flakes, aggregated particles, and nanosheet stacks, respectively. The $\mathrm{I}_{2}$ uptake of the CCBCP-CMP sample $\left[11.56 \mathrm{wt}\left(\mathrm{m}^{-2} \mathrm{~g}^{-1}\right)\right]$ was higher than those of the other precursors because of its high surface area and high content of N-heteroatoms. Recently, we used Friedel-Crafts polymerization to prepare the hybrid inorganic/organic porous materials POSS-TPE and POSS-TPP based on cubic octavinylsilsesquioxane (OVS) and tetraphenylethene and tetraphenylpyrazine units, respectively. The as-prepared POSS-TPE had a high surface area $\left(741 \mathrm{~m}^{2} \mathrm{~g}^{-1}\right)$ and good thermal stability, as determined using $\mathrm{N}_{2}$ adsorption/ desorption and TGA, respectively. ${ }^{109}$ The Alameddine group prepared five CMP materials through Cu-catalyzed [4+2] benzannulations of 2,5-bis(phenylethynyl)tetraphthaldehyde with a series of 1,4-diarylethynyltriptycene derivatives. ${ }^{110}$ The resultant CMPs 1-5 were microporous, with high BET surface areas $\left(794 \mathrm{~m}^{2} \mathrm{~g}^{-1}\right)$ and pore volumes $\left(0.63 \mathrm{~cm}^{-3} \mathrm{~g}^{-1}\right)$, and displayed good $\mathrm{I}_{2}$ uptake (166 wt\%). Lin et al. constructed CTT-POP1, a POP containing triaryl triazine and featuring intramolecular hydrogen bonds, that functioned as an adsorbent for the dye methylene blue because of its surface wettability and capability for $\pi-\pi$ interactions. ${ }^{111}$ The Das group prepared a series of covalent organic polymers (COPs) through the reactions of triptycene with derivatives of benzene1,3,5-tricarboxaldehyde. ${ }^{112}$ Interestingly, the surface areas of these resulting polymers were strongly affected by the number of $\mathrm{OH}$ groups in the I-COPs, as predicted from the BET profiles. Due to their high surface areas and uniform spherical shapes, determined 
(a)

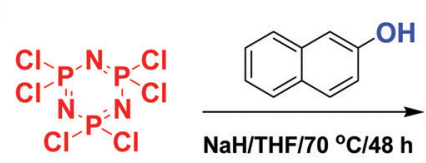<smiles></smiles>

PN-Nap-1

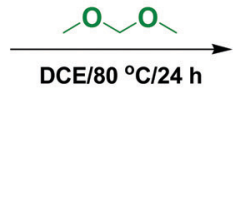

(b)

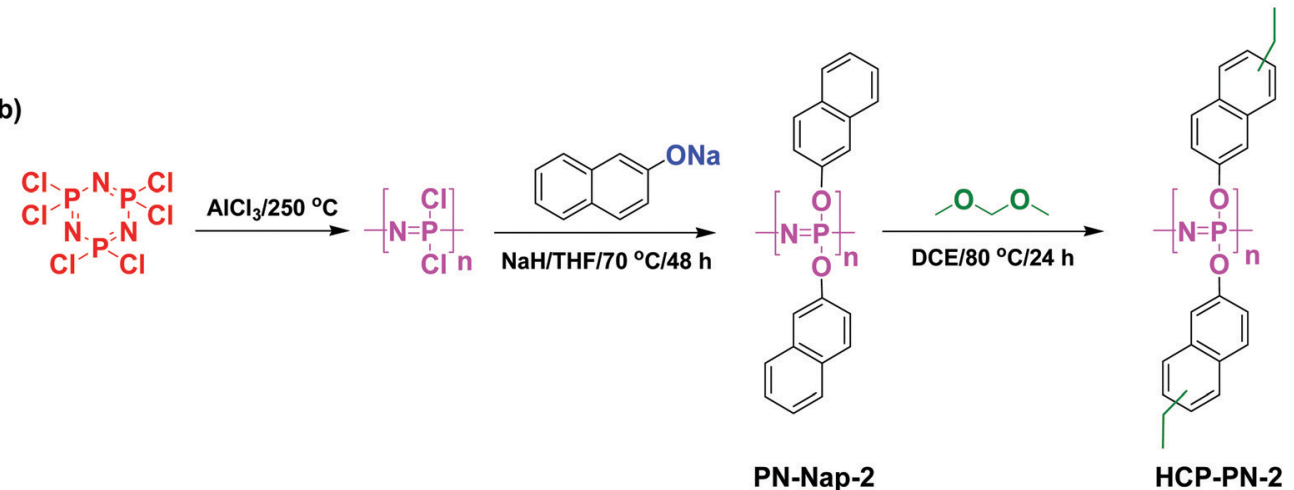

PN-Nap-2

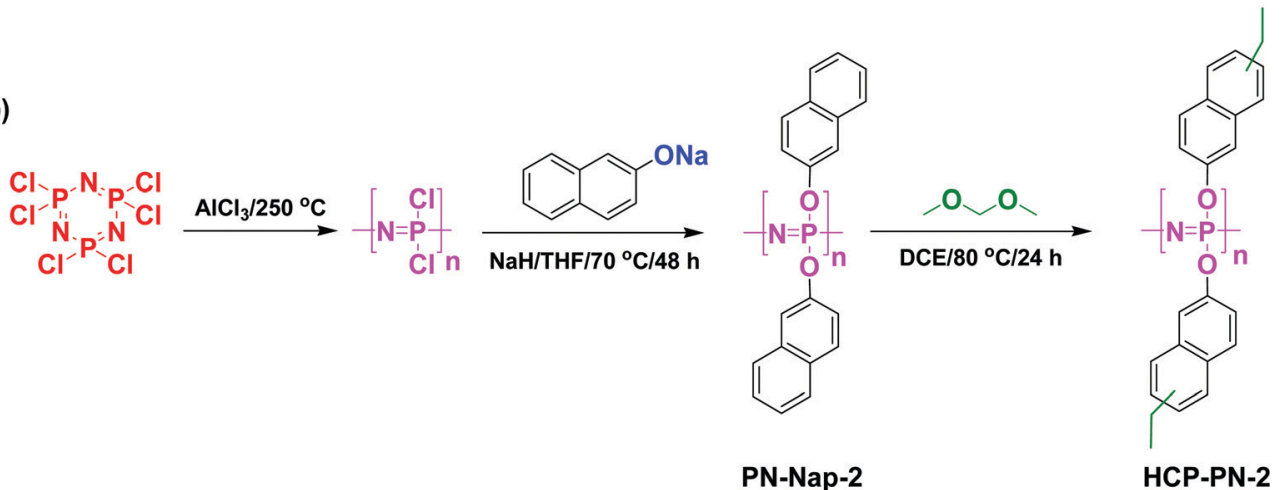<smiles>CCCCc1ccc2cc(CC)ccc2c1</smiles>

HCP-PN-1

Fig. 8 Synthesis of (a) PN-Nap-2 and HCP-PN-2, (b) and (c) $\mathrm{CO}_{2}$ adsorption of PN-Nap-2 and HCP-PN-2 at 0 and $25^{\circ} \mathrm{C}$. Reproduced from ref. 97 with permission from American Chemical Society.

(a)

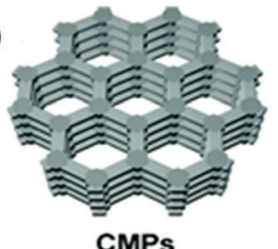

CMPs

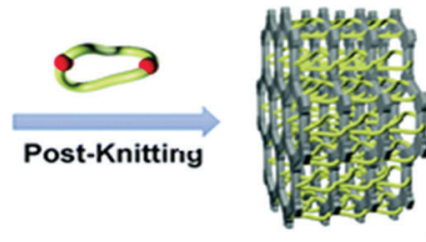

KCMPs

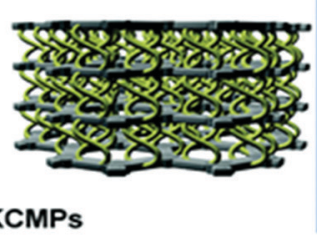

(b)

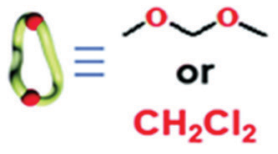

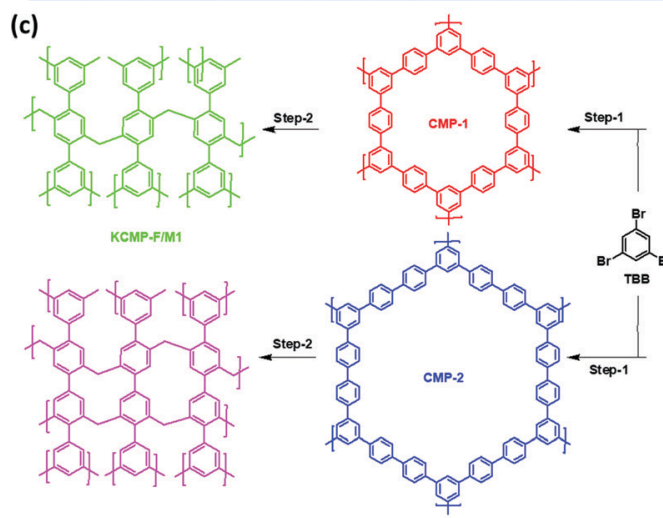
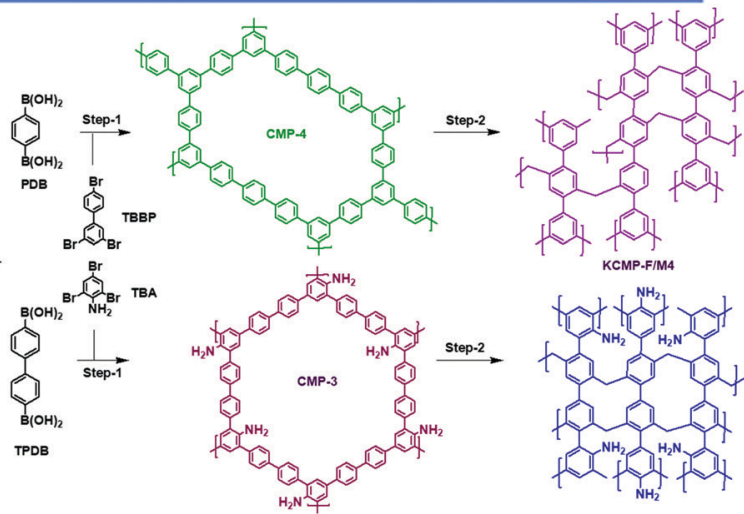

KCMP-FIM3

Fig. 9 Schematic cartoon for the synthesis of CMPs via the post-knitting method. (b) The cross-linker structure. (c) The synthetic routes for the KCMP via palladium-catalyzed Suzuki coupling and a Lewis acid catalyzed Friedel-Crafts reaction. Reproduced from ref. 100 with permission from the Royal Society of Chemistry.

from SEM images, the $\mathrm{I}_{2}$ capacities of these I-COPs were outstanding ( $c a .4860 \mathrm{mg} \mathrm{g}^{-1}$ ) when compared with those of other
COP materials. The ability to tune the charge density of COFs, when combined with their high crystallinities and high surface 
(a)
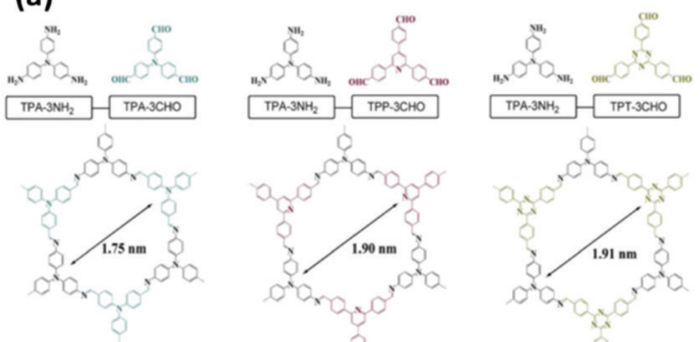

(c)

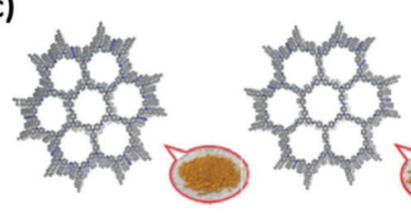

(b)

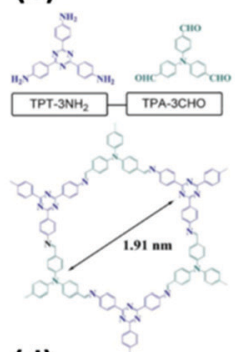

(d)

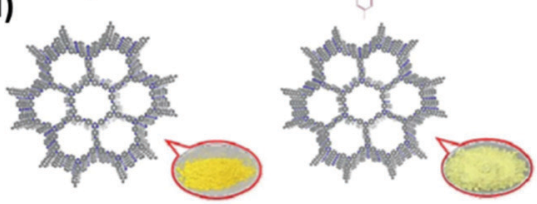

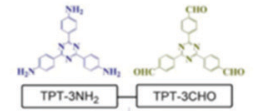
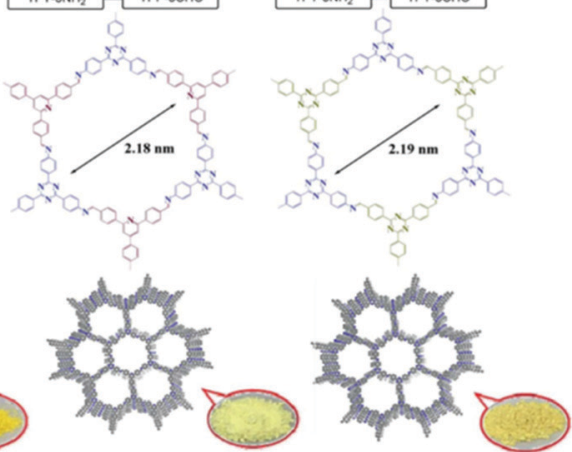

TPA-TPA-COF (TPA-COF-1) TPA-TPP-COF (TPA-COF-2) TPA-TPT-COF (TPA-COF-3) TPT-TPA-COF (TPT-COF-4) TPT-TPP-COF (TPT-COF-5) TPT-TPT-COF (TPT-COF-6)

Fig. 10 (a and b) Synthesis of TPA-COF-1, TPA-COF-2, TPA-COF-3, TPT-COF-1, TPT-COF-2, and TPT-COF-3 through Schiff base reactions. (c and d) Their color photos. Reproduced from ref. 104 with permission from the Royal Society of Chemistry.<smiles>Nc1ccc(N(c2ccc(N)cc2)c2ccc(N)cc2)cc1</smiles><smiles>Nc1ccc(-c2cc(-c3ccc(N)cc3)cc(-c3ccc(N)cc3)c2)cc1</smiles>

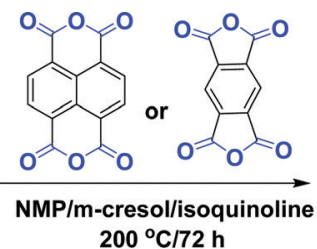<smiles>C1CC1</smiles><smiles>Cc1cc(C)cc(C)c1</smiles><smiles>Cc1cc(C)cc(C)c1</smiles>

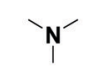<smiles>C=C=Cc1cc2c(cc1C)CSc1cc(C)c(C)cc1C2</smiles><smiles>Cc1cccc(C)c1C</smiles>

PIA

PIB

PIC

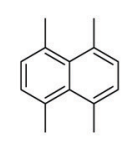

PID

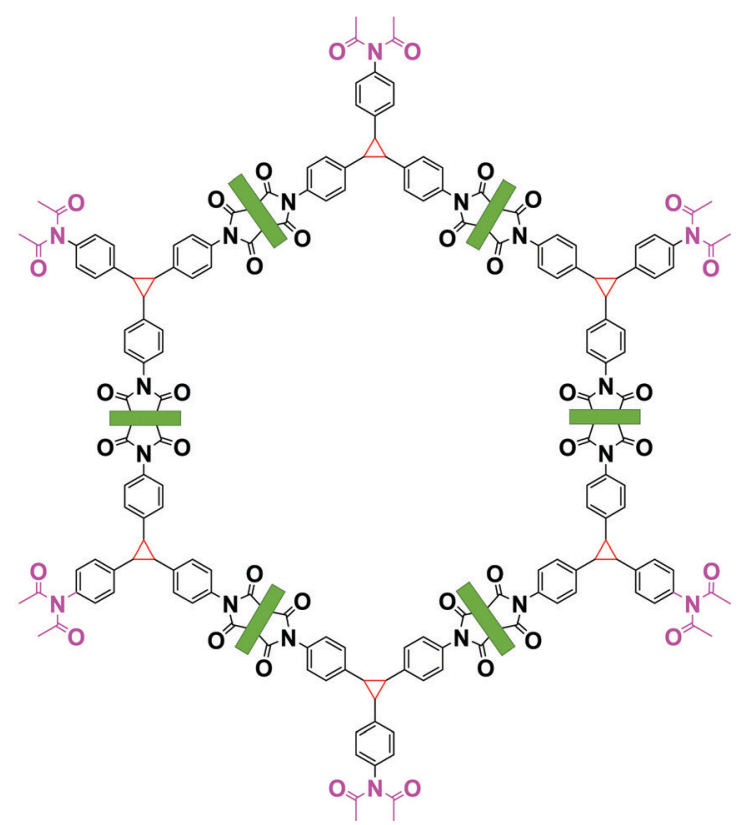

Fig. 11 Synthesis of the four polyimide COFs. Reproduced from ref. 106 with permission from American Chemical Society.

areas, makes them good candidates for capturing various chemicals, including dyes. Our group employed the previously mentioned BFTB-PyTA, BFTB-BFTB, and BFTB-BCTA COFs for dye adsorption; the adsorption efficacies of the hollow-structured BFTB-PyTA and BFTB-BFTB COFs were higher than that of the non-hollow-structured BFTB-BCTA COF. These COFs displayed excellent adsorption performance (up to 99.2\%) and confirmed that the controlling parameters of dye adsorption in the COFs were the surface area, the morphology, and the capability for $\pi$-stacking with the dye. ${ }^{113}$ 
(a)

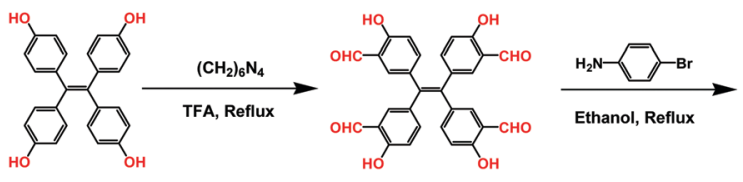

(c)

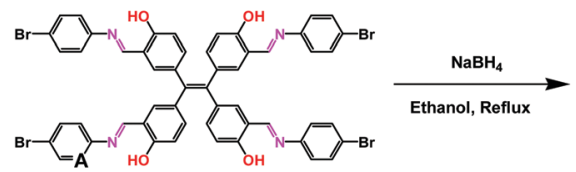

(d)

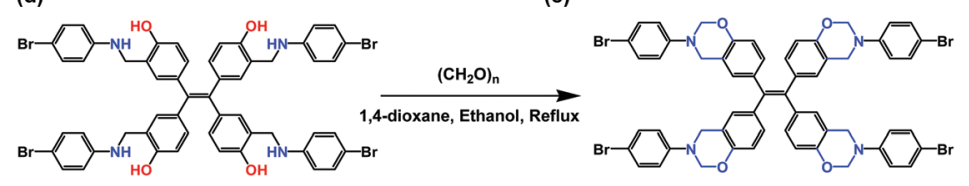

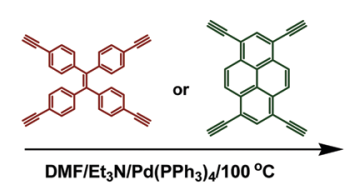

(f)

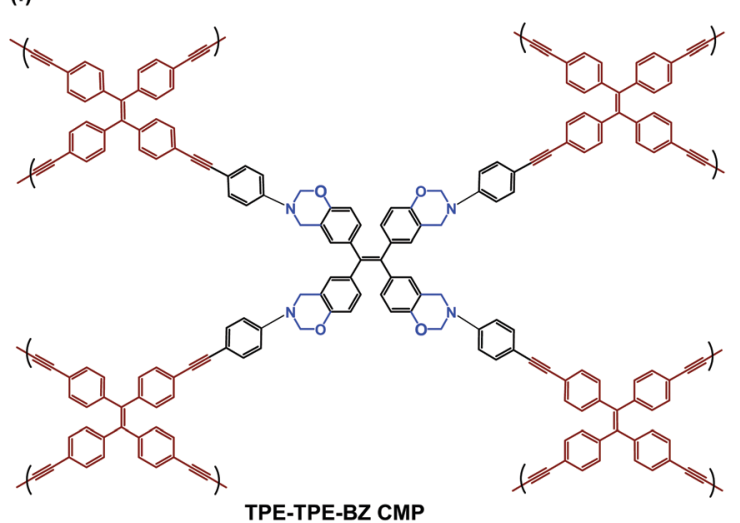

(g)

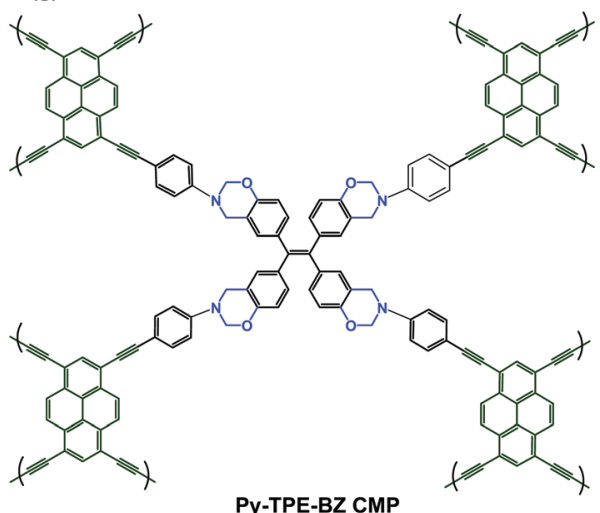

Fig. 12 Synthesis of the TPE-TPE-BZ CMP, and TPE-TPE-BZ CMPs through a multistep reaction. Reproduced from ref. 107 with permission from American Chemical Society.

\subsection{Energy storage}

There are many reports of the use of POPs as excellent materials for energy storage. For example, we have prepared microporous CTFs based on pyrene units (Pyrene-CTF-10, and Pyrene-CTF20) through ionothermal reactions of 1,3,6,8-cyanopyrene (TCNPy) with different mole ratios of $\mathrm{ZnCl}_{2}$ at $500{ }^{\circ} \mathrm{C}$. ${ }^{114}$ Pyrene-CTF-10 and Pyrene-CTF-20 possessed high surface areas (819 and $1019 \mathrm{~m}^{2} \mathrm{~g}^{-1}$, respectively) and capacitances (380 and $500 \mathrm{~F} \mathrm{~g}^{-1}$, respectively). We have also prepared bicarbazolebased CTFs (Car-CTFs) based on Car-4CN. According to TGA and $\mathrm{N}_{2}$ adsorption/desorption analyses, our Car-CTFs had high specific surface areas (up to $1400 \mathrm{~m}^{2} \mathrm{~g}^{-1}$ ), and excellent coulombic efficiencies. ${ }^{115}$ Mohamed et al. synthesized two HCPS (TPE-CPOP1, and TPE-CPOP2) based on tetraphenylethene as the main building unit and these obtained materials had high BET surface areas, amorphous structures, and high specific capacitances. ${ }^{116}$ Furthermore, we prepared An-CPOP1 and An-CPOP2 through simple Friedel-Crafts alkylations of $\mathrm{An}-4 \mathrm{Ph}$ with 2,4,6-trichloro-1,3,5-triazine and formaldehyde dimethyl acetal as crosslinker reagents. ${ }^{117}$ An-CPOP1 possessed a tubular nanotube structure, based on SEM imaging, while An-CPOP2 displayed a capacitance of $98.10 \mathrm{~F} \mathrm{~g}^{-1}$ at $0.5 \mathrm{~A} \mathrm{~g}^{-1}$. Mohamed et al. prepared DPT-HPP through a Friedel-Crafts reaction of (4-(5,6-diphenyl- $1 H$-benzimidazol-2-yl)triphenylamine in the presence of $\mathrm{FeCl}_{3}$; it exhibited a specific capacitance of $110 \mathrm{~F} \mathrm{~g}^{-1}$ and excellent cycling stability over 2000 cycles. ${ }^{118}$ We reported the TPPDATPPyr and TPPDA-TPTPE COFs prepared through Schiff-base condensations of TPPDA $\left(\mathrm{NH}_{2}\right)_{4}$ with TPPyr $(\mathrm{CHO})_{4}$ and TPTPE(CHO $)_{4}$, respectively. ${ }^{119}$ The TPPDATPPyr and TPPDA-TPTPE COFs were highly thermally resistant, with decomposition temperatures $\left(T_{\mathrm{d} 10}\right)$ of up to 543 and $551{ }^{\circ} \mathrm{C}$, respectively; in addition, they had high surface areas (up to 1020 and $1067 \mathrm{~m}^{2} \mathrm{~g}^{-1}$, respectively). Both the TPPDATPPyr and TPPDA-TPTPE COFs underwent reversible redox processes at a low sweep rate $\left(5 \mathrm{mV} \mathrm{s}^{-1}\right)$ over the potential range from +0.18 to $-0.92 \mathrm{~V}$, because of their redox-active triphenylamino groups. At a current density of $2 \mathrm{~A} \mathrm{~g}^{-1}$, the specific capacitance of the TPPDA-TPTPE COF $\left(237.1 \mathrm{~F} \mathrm{~g}^{-1}\right)$ was higher than that of the TPPDATPPyr COF $\left(188.7 \mathrm{~F} \mathrm{~g}^{-1}\right)$, due to the higher surface area of the former, as well as the easy access for electrolytes to its electrode surface, thanks to the presence of the heteroatoms. Furthermore, the TPPDATPPyr and TPPDATPTPE COFs displayed excellent cycling capacities, with retentions of up to 86.2 and $85.6 \%$, respectively, after 5000 cycles. We have examined the effect of the COF surface area on capacitance through the formation of a sponge-like shell TPTDAHQ COF through the template-free condensation of TPT$3 \mathrm{CHO}$ and DAHQ-2HCl. ${ }^{120}$ The TPT-DAHQ COF possessed an 

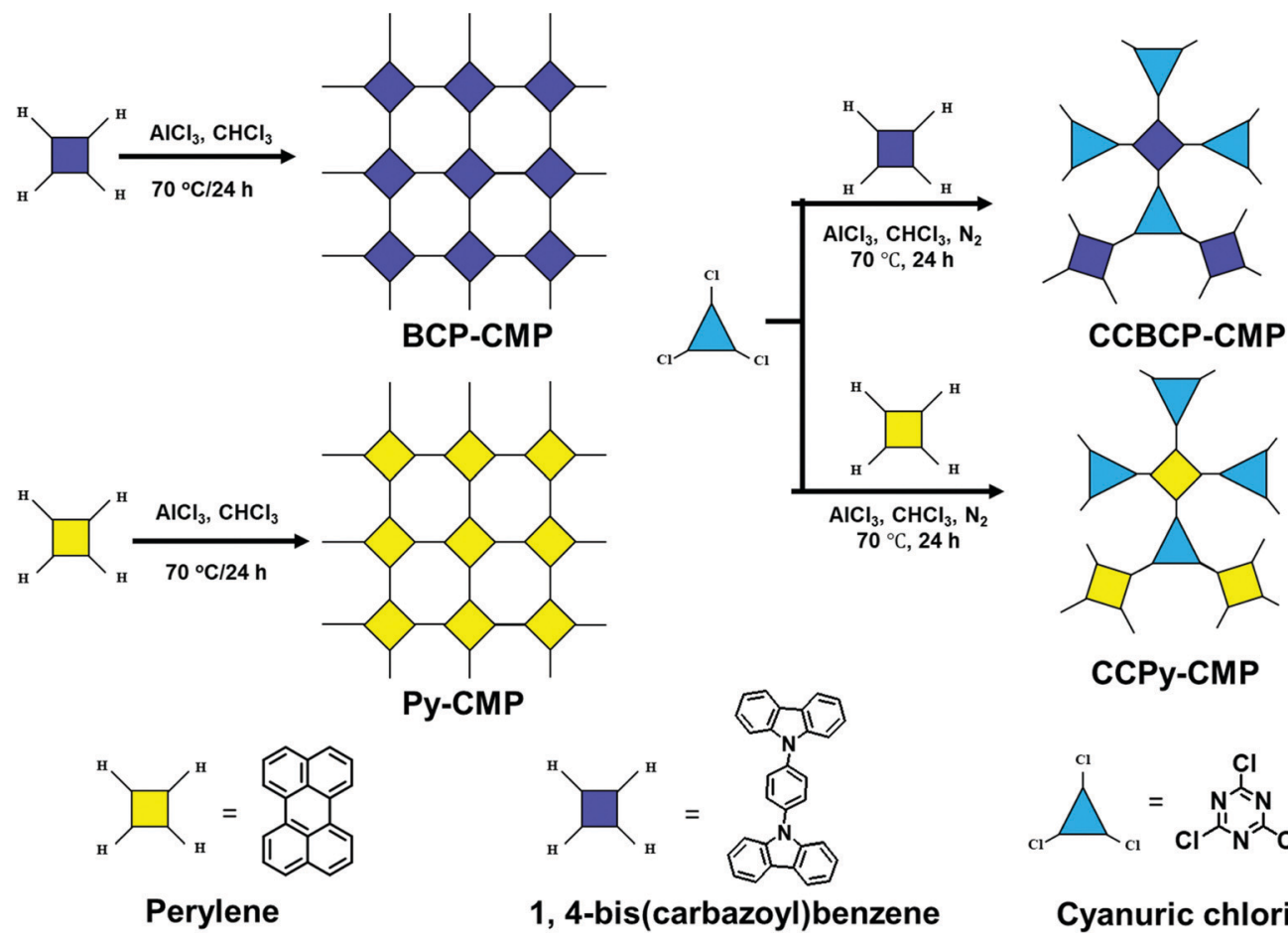

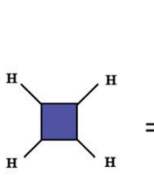

1, 4-bis(carbazoyl)benzene

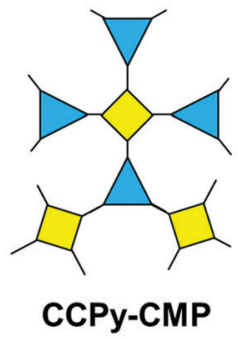

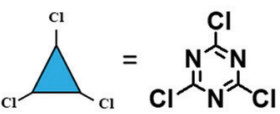

Cyanuric chloride

Fig. 13 Synthesis routes for BCB-CMP, Py-CMP, CCBCB-CMP and CCPy-CMP. Reproduced from ref. 108 with permission from Elsevier.

extraordinary surface area (up to $1855 \mathrm{~m}^{2} \mathrm{~g}^{-1}$ ) in addition to high thermal resistance (up to $452^{\circ} \mathrm{C}$ ). The high surface area of the TPT-DAHQ COF was the main factor behind its excellent capacitance (up to $256 \mathrm{~F} \mathrm{~g}^{-1}$ at current density of $0.5 \mathrm{~A} \mathrm{~g}^{-1}$ ); it displayed high durability, with up to $98.8 \%$ of its original capacitance retained without any obvious degradation after 1850 cycles at $10 \mathrm{~A} \mathrm{~g}^{-1}$. We also elucidated the effect of the active redox sites in COFs structures through one-pot syntheses of three biflurorenylidene-based COFs BFTB-PyTA, BFTB-BFTB, and BFTB-BCTA through reactions of BFTB-4CHO with PyTA$4 \mathrm{NH}_{2}$, BFTB- $4 \mathrm{NH}_{2}$, and BCTA-4 $\mathrm{NH}_{2}$, respectively. ${ }^{113}$ In addition to the BFTB-PyTA, BFTB-BFTB, and BFTB-BCTA COFs displaying record-high thermal resistances of up to 433,416 , and $449{ }^{\circ} \mathrm{C}$, respectively, they also exhibited high BET surface areas (up to 1133,1040 , and $834 \mathrm{~m}^{2} \mathrm{~g}^{-1}$, respectively), determined through $\mathrm{N}_{2}$ isothermal analyses at $77 \mathrm{~K}$. The specific capacitances of the BFTВ-РуTA and ВFTB-BFTB COFs were 68.0 and $84.5 \mathrm{~F} \mathrm{~g}^{-1}$, respectively, at a scan rate of $5 \mathrm{mV} \mathrm{s}^{-1}$; the specific capacitance of the BFTB-BCTA COF at the same scan rate was higher $\left(89.9 \mathrm{~F} \mathrm{~g}^{-1}\right)$, although it had the lowest surface area, revealing that the redox-active sites were the carbazole subunits. Furthermore, the smooth surface morphology of the BFTB-BFTB COF played an important role in its specific capacitance being higher than that of the BFTB-РуTA COF, which had a hollow-microtubule structure. The capacitive retentions of the BFTB-РyTA, BFTB-BFTB, and BFTB-BCTA COFs were 97.27, 85.23, and 91.21\%, respectively. Using our previously mentioned TFP-COFs, we investigated the effects of redox-active amino, pyridine, and carbazole groups on the reversible redox processes occurring at a low sweep rate of $5 \mathrm{mV} \mathrm{s}^{-1}$. The specific capacitance of the TFP-TPA COF (up to $291.1 \mathrm{~F} \mathrm{~g}^{-1}$ ) was higher than those of the TFP-TPP and TFP-Car COFs, due to its higher nitrogen-atom percentage; therefore, it had a greater number of available redox active sites, even though it had a lower surface area. The TFP-TPA COF, TFP-TPP and TFP-Car COFs exhibited high durability after 5000 cycles at $10 \mathrm{~A} \mathrm{~g}^{-1}$, with retention of their original values of up to $91,88.2$, and $90.4 \%$, respectively. ${ }^{105}$ Triphenylamine has been a highly studied redox-active unit because of its ability to store energy. Our group investigated the previously mentioned COFs 1-6 to test their validity as supercapacitors. Indeed, the TPA-COFs 1-4 exhibited supercapacitance, whereas the TPTCOFs 5 and 6 did not provide any redox curves during cyclic voltammetry, consistent with their absence of triphenylamine moieties. Notably, the unsaturated $\mathrm{N}=\mathrm{C}$ units do not display any reactivity in acidic media, and increasing the number of triphenylamine groups enhanced the specific capacitance; as a result, the capacitance of TPA-TPA-COF-1, which featured six triphenylamine groups, was higher than those of the other COFs 2-4. Morphologies and chemical structures can also play a role in affecting the specific capacitances of supercapacitors. We confirmed these phenomena in a recent study of the previously mentioned Car-TPA, Car-TPP, and Car-TPT COFs, which possessed carbazole, pyridine, and triphenylamine units, respectively, making them ideal candidates for storing energy; at $0.2 \mathrm{~A} \mathrm{~g}^{-1}$, they displayed specific capacitances of 13.6, 14.5, and $17.4 \mathrm{~F} \mathrm{~g}^{-1}$, respectively. ${ }^{103}$ The Car-TPA and Car-TPP COFs had high surface areas and two redox groups, but provided lower capacitances; in contrast, the Car-TPT COF had a low surface area and only one redox group, but its microtubular structure and molecular design led to enhanced capacitance 
(a)

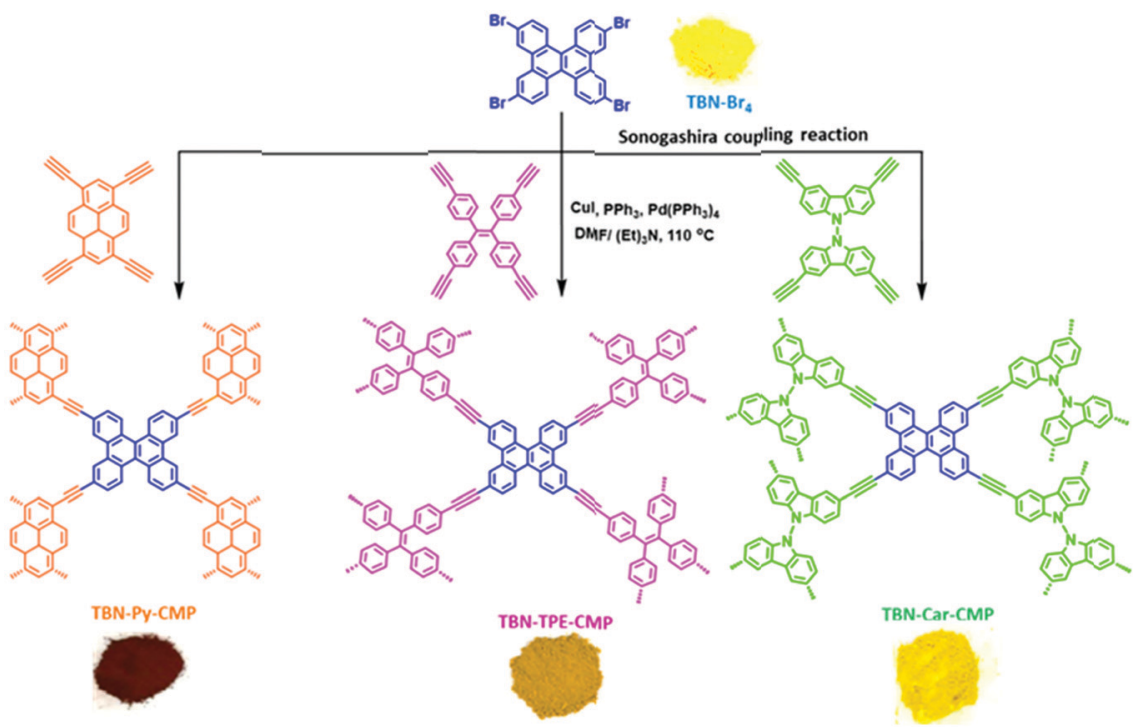

(b)
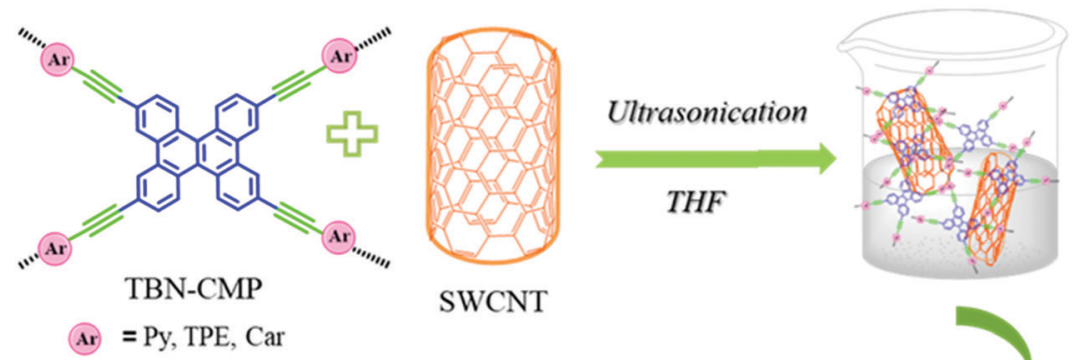

(d)
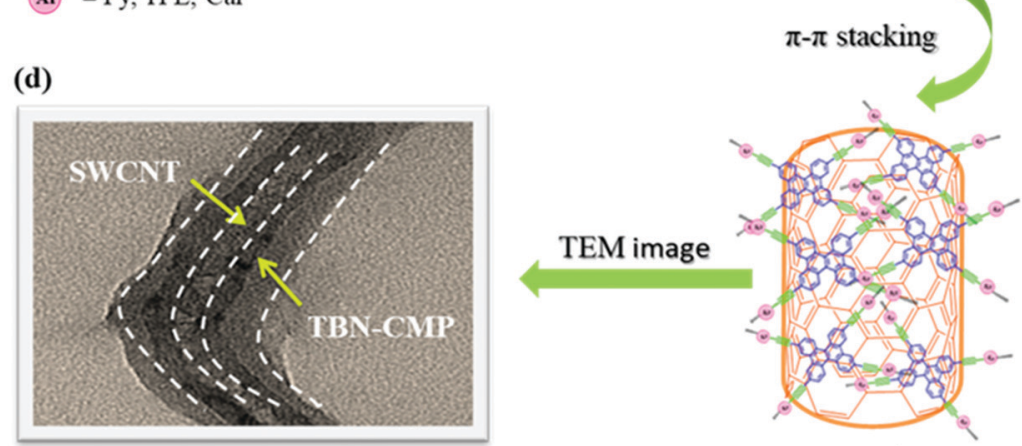

Fig. 14 (a) Synthesis of TBN-Py-CMP, TBN-TPE-CMP, and TBN-Car-CMP and (b) formation of TBN-CMP/SWCNTs. Reproduced from ref. 121 with permission from American Chemical Society.

and retention during the charging/discharging process. Recently, Maha et al. used Sonogashira-Hagihara reactions to prepare a series of CMPs based on tetrabenzonaphthalene (TBN) moieties (TBN-TPE-CMP, TBN-Py-CMP, and TBN-CarCMP) [Fig. 14(a)]. ${ }^{121}$ Subsequently, we improved the conductivity of these materials by mixing them with single-walled carbon nanotubes (SWCNTs) [Fig. 14(b)]. Interestingly, the capacitance of the TBN-Py-CMP/SWCNT nanocomposite (430 $\mathrm{F} \mathrm{g}^{-1}$ at $0.5 \mathrm{~A} \mathrm{~g}^{-1}$ ) was higher than those of the other samples, presumably because of strong $\pi-\pi$ interactions between the pyrene units in the TBN-Py-CMP framework and the SWCNTs. ${ }^{122-125}$ Eddaoudi et al. prepared Hex-Aza-COF-2 and Hex-Aza-COF-3 through solvothermal condensations of benzoquinone with redox-functionalized aromatic tetramines and phenazine, respectively [Fig. 15(a)]. ${ }^{126}$ They used powder X-ray diffraction (PXRD), solid state NMR spectroscopy, BET analysis, SEM, and TEM imaging to investigate the chemical structures, crystallinities, porosities, and morphologies of these materials [Fig. 15(b)-(i)]. The PXRD data and SEM images revealed that both materials had moderate crystallinities and aggregated spherical morphologies. Furthermore, based on electrochemical measurements, the specific capacitances of Hex-Aza-COF-2 $\left(585 \mathrm{~F} \mathrm{~g}^{-1}\right)$ and Hex-Aza-COF-3 $\left(663 \mathrm{~F} \mathrm{~g}^{-1}\right)$ were higher than those reported previously for porous polymeric and COF materials. Yang et al. prepared a new porous organic HCP through the reaction of pyrene with $\mathrm{CHCl}_{3}$ as the crosslinker and $\mathrm{AlCl}_{3}$ as the catalyst, with the subsequent hydrolysis affording HcPPy that possessed a high surface area $\left(723 \mathrm{~m}^{2} \mathrm{~g}^{-1}\right)$ and 
a)

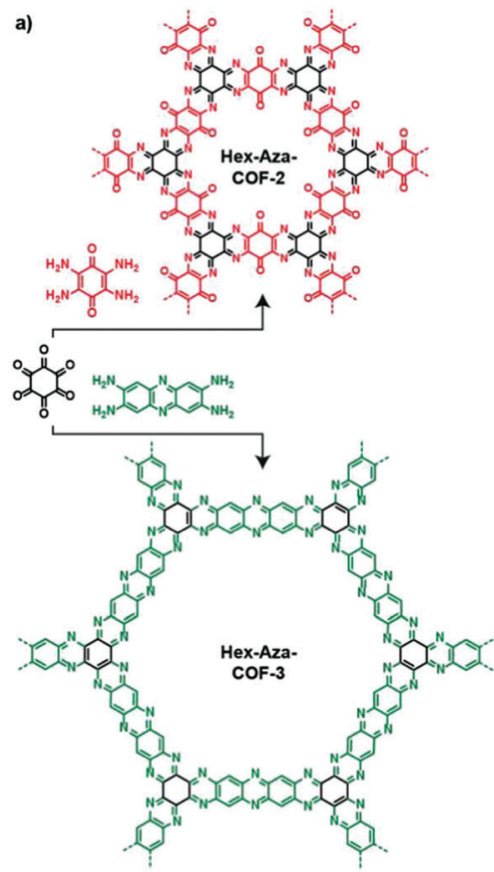

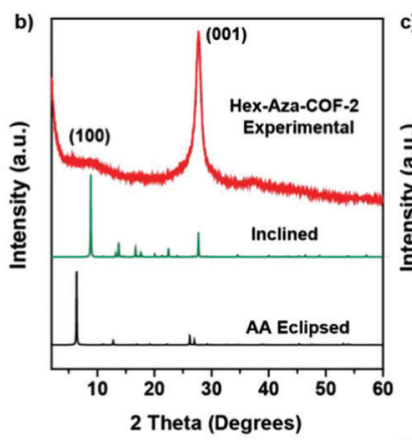
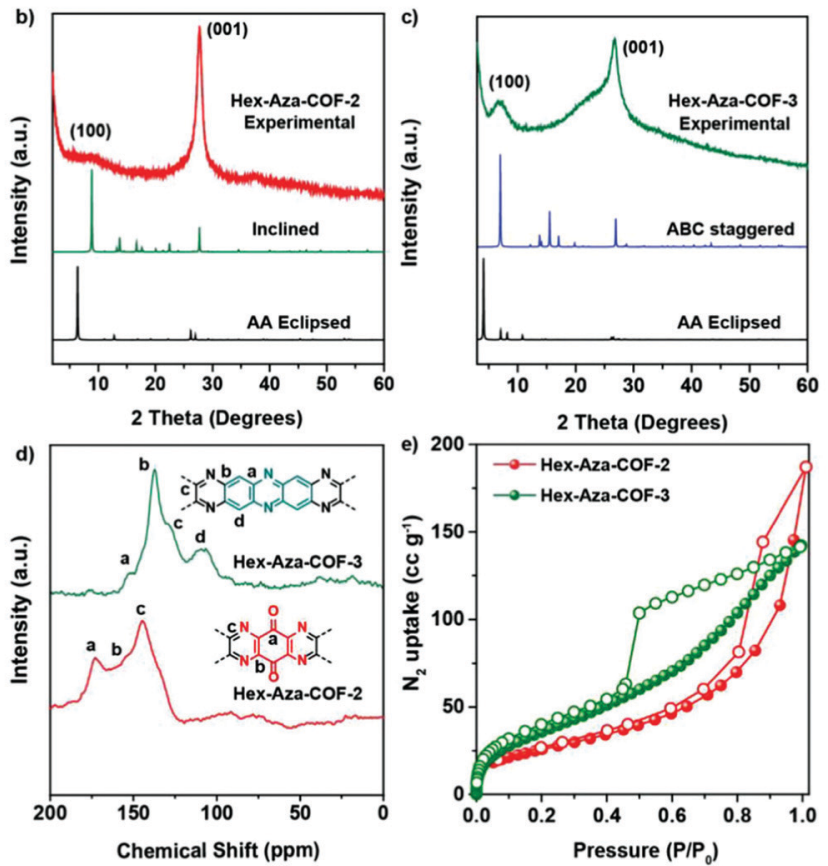

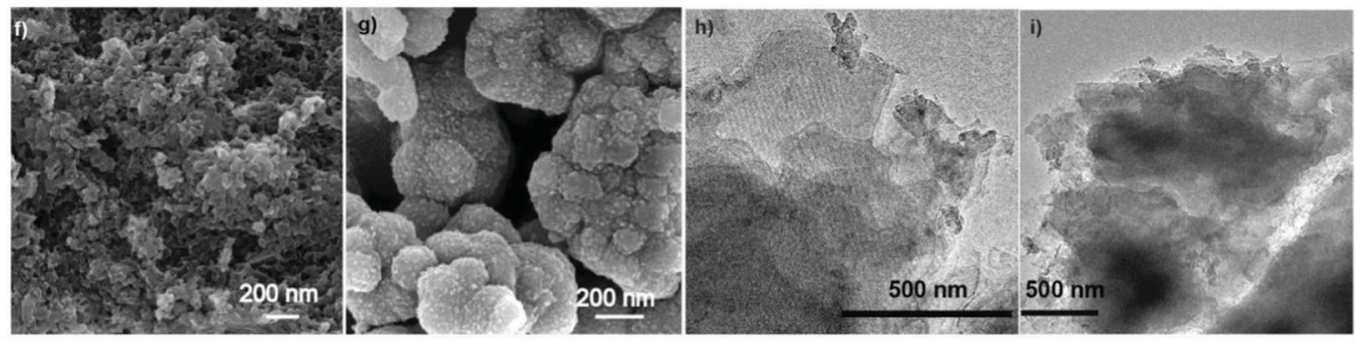

Fig. 15 (a) Synthesis of Hex-Aza-2 and Hex-Aza-COF-3, (b) and (c) PXRD pattern for Hex-Aza-COF-2 and Hex-Aza-COF-3. (d) Solid-state ${ }^{13}$ C NMR for Hex-Aza-COF-2 and Hex-Aza-COF-3. (e) BET isotherms for Hex-Aza-COF-2 and Hex-Aza-COF-3. (f and g) SEM images for Hex-Aza-COF-2 and Hex-Aza-COF-3. (h and i) TEM images for Hex-Aza-COF-2 and Hex-Aza-COF-3. Reproduced from ref. 126 with permission from Wiley-VCH.

micropores $(1 \mathrm{~nm})$ and mesopores $(2-3$ and $3.5-4.5 \mathrm{~nm}) .{ }^{127}$ This material functioned as an anode in $\mathrm{Li}$ batteries and provided excellent current densities (up to $683 \mathrm{MA} \mathrm{h} \mathrm{g}^{-1}$ at $\left.1000 \mathrm{~mA} \mathrm{~g}^{-1}\right)$. Wong et al. prepared materials named SP and HP through Sonogashira couplings of tri(4-ethynylphenylamine) with 9-ferrocenylidene-2,7-diiodo-9 $H$-fluorene in the presence and absence of ZIF-67, respectively. ${ }^{128}$ They then prepared Fe-embedded magnetic carbon materials (SP and HP-MCMs) through the carbonization of SP and HP at $500{ }^{\circ} \mathrm{C}$ for $1 \mathrm{~h}$. The obtained spherical SP-MCP had a microporous architecture, good redox performance, and good cycling stability when applied in lithium-ion batteries (LIBs) as an anode; its performance was superior to that of the HP-MCP. Zhao et al. prepared the 2D-COF-ETTA-ETTCA and COF-ETTA-ETTCA-S materials by loading $88.4 \mathrm{wt} \%$ of sulfur and applied these materials in lithium-sulfur batteries. ${ }^{129}$ The devices displayed high capacity (up to $1617 \mathrm{~mA} \mathrm{~h} \mathrm{~g}{ }^{-1}$ at $0.1 \mathrm{C}$ ), low capacitance decay after 528 cycles, and high coulombic performance (ca. 98\%).

\subsection{Hydrogen evolution}

Chi et al. synthesized a new electrochemical material $\left(\mathrm{PMO}_{10} \mathrm{~V}_{2}\right.$ @CTF) through the fabrication of $\mathrm{PMO}_{10} \mathrm{~V}_{2}$ with a cationic CTF as a support, itself prepared through trimerization of 1,3-bis(4-cyanophenyl)imidazolium chloride. $\mathrm{PMO}_{10} \mathrm{~V}_{2} @ \mathrm{CTF}$ functioned as the catalyst for the production of benzaldehyde and $\mathrm{H}_{2}$ through the oxidation of benzyl alcohol. ${ }^{130}$ Recently, der Voort et al. prepared metal-free electrocatalysts based on porous BINOL-CTF materials featuring various nitrogencontaining groups (pyridine-N-oxide, pyrrolic- $\mathrm{N}$, quaternary-N, and pyridinic-N/triazine- $\mathrm{N}$ units) through cyclization reactions of $2,2^{\prime}$-dihydroxy[1,1'-binaphthalene]-6,6'-dicarbonitrile as the $\mathrm{C}$ and $\mathrm{N}$ atom sources in molten $\mathrm{ZnCl}_{2}$ at 400 and $500{ }^{\circ} \mathrm{C}$, respectively. ${ }^{131}$ BINOL-10-500 displayed outstanding performance in the hydrogen evolution reaction (HER) and oxygen reduction reaction (ORR), relative to the other CTF samples, as a result of its large pores, high specific surface area, and high quaternary- $\mathrm{N}$ content. Recently, COFs have garnered an exciting position in the field of $\mathrm{H}_{2}$ production because of their ability to facilitate charge transfer and light harvesting. Accordingly, our group applied two of the previously mentioned COFs (PyTA-BC, and PyTA-BC-Ph), based on their excellent photophysical properties, as photocatalysts for $\mathrm{H}_{2}$ evolution from water in the presence of a sacrificial electron donor. The PyTA-BC and PyTA-BC-Ph COFs provided photocatalytic activities of up to 
1183 and $417 \mu \mathrm{mol} \mathrm{g}{ }^{-1} \mathrm{~h}^{-1}$, respectively, in the presence of ascorbic acid as the electron donor. ${ }^{132}$ Jiang et al. prepared, through the in situ growth of TFPT-DETH on the octahedral $\mathrm{NH}_{2}$-UiO-66 surface, an $\mathrm{NH}_{2}$-UiO-66@TFPT-DETH core-shell hetero-framework possessing an octahedral morphology, a smooth surface, a high surface area, light absorption properties, and both meso- and microporous structures; it mediated a high degree of $\mathrm{H}_{2}$ production from water (up to $7178 \mathrm{mmol} \mathrm{g}^{-1} \mathrm{~h}^{-1}$ ) (Fig. 16). ${ }^{133}$ Interestingly, Guo et al. prepared multivariate $\mathrm{Tp}\left(\mathrm{BTxTP}_{1-x}\right)$-COFs for photocatalytic $\mathrm{H}_{2}$ evolution from water through condensation of the monomer 1,3,5-triformylphloroglucinol (Tp) with tertiary phenyl (TP) and benzothiadiazole-derived (BT) units [Fig. 17(a)]. ${ }^{134}$ FTIR and solid state NMR spectroscopy confirmed the chemical structures of the resulting COFs, which possessed highly crystalline structures and high surface areas $\left(>700 \mathrm{~m}^{2} \mathrm{~g}^{-1}\right)$ [Fig. 17(b)-(e)]. The $\mathrm{H}_{2}$ evolution rate increased to $9839 \mu \mathrm{mol} \mathrm{g}^{-1} \mathrm{~h}^{-1}$ when the COF material contained $5 \mathrm{~mol} \%$ of BT.

\subsection{Chemical sensing}

Laskar et al. prepared two branched conjugated mesoporous polymers (CMO1 and CMO2) displaying aggregation-induced emission and high quantum yields. ${ }^{135}$ CMO1 was more sensitive than CMO2 towards trinitrotoluene (TNT) and picric acid, due to the higher pore density and size in CMO1. The Zhong group prepared a highly fluorescent F-CTF-3 porous framework through the condensation of phenamidine hydrochloride with 4,4'-(benzo[c][1,2,5]thiadiazole-4,7-diyl)dibenzaldehyde. ${ }^{136}$ This fluorescent material functioned as a chemical sensor for phenylamine (PA) and phenylenediamine (PDA), with detection at concentrations of 11.7 and $1.47 \mathrm{nM}$, respectively. The excellent luminescence features of COFs can arise in addition to

(a)

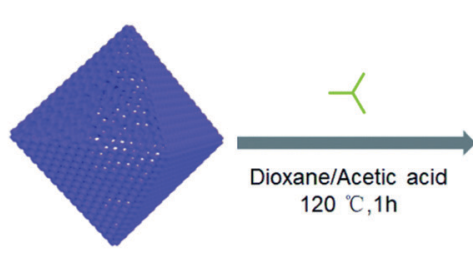

$\mathrm{NH}_{2}-\mathrm{UiO}-66$

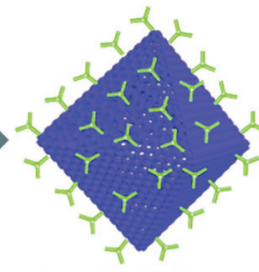

$\mathrm{NH}_{2}$-UiO-66@TFPT
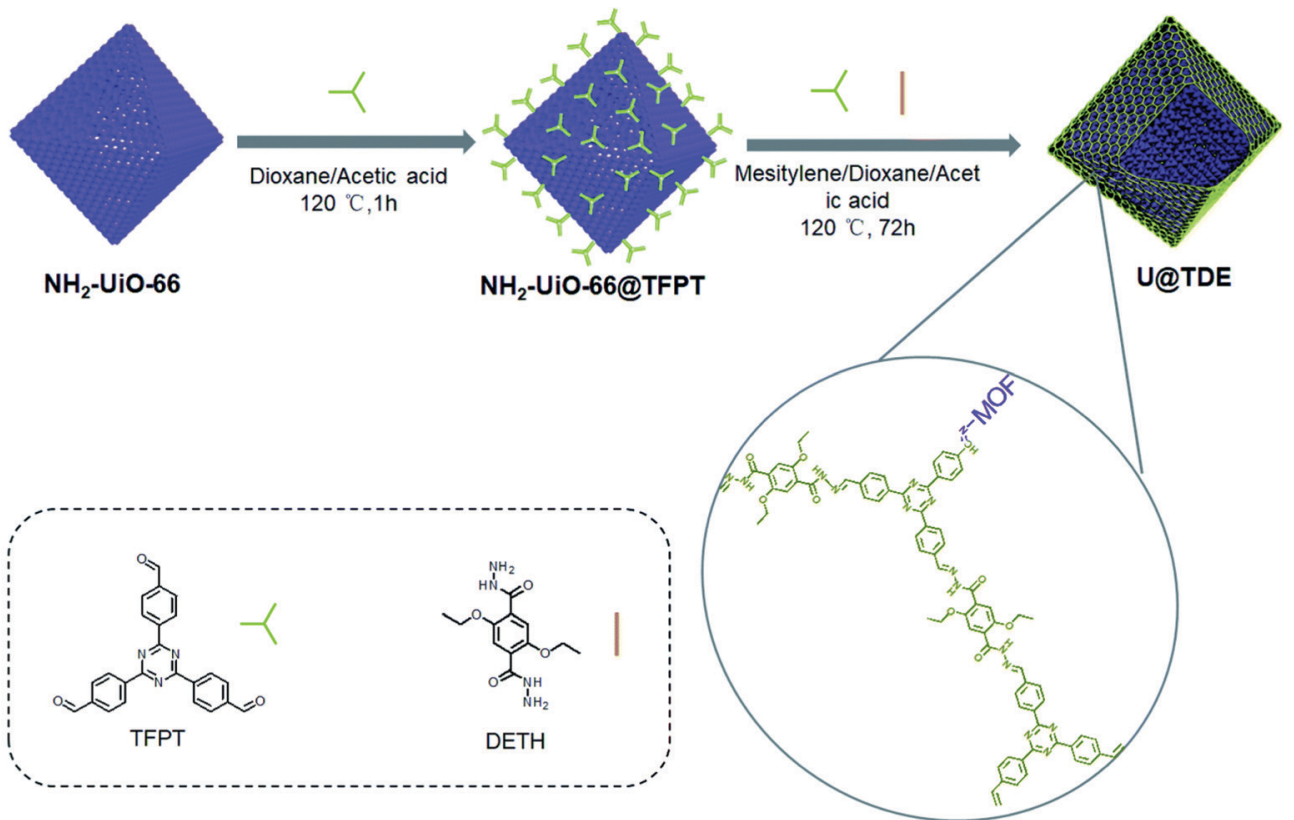

(b)

(e)

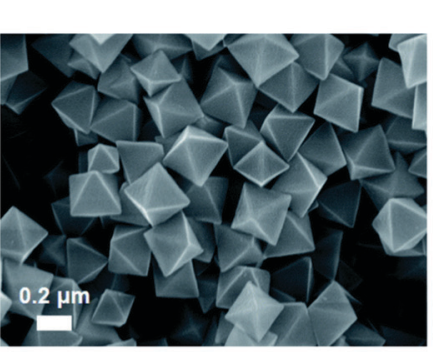

(c)

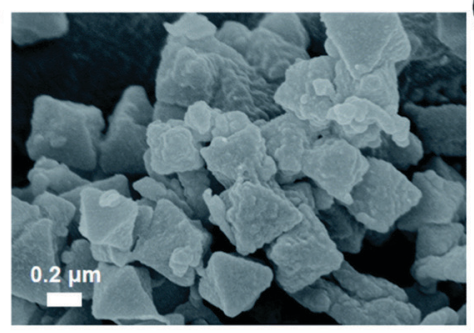

(d)

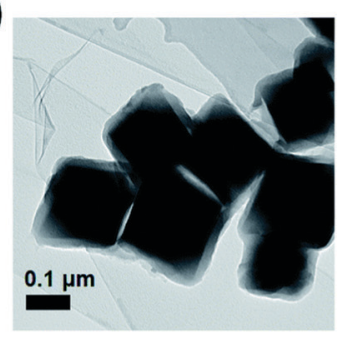

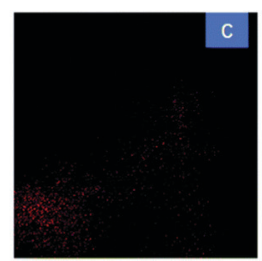
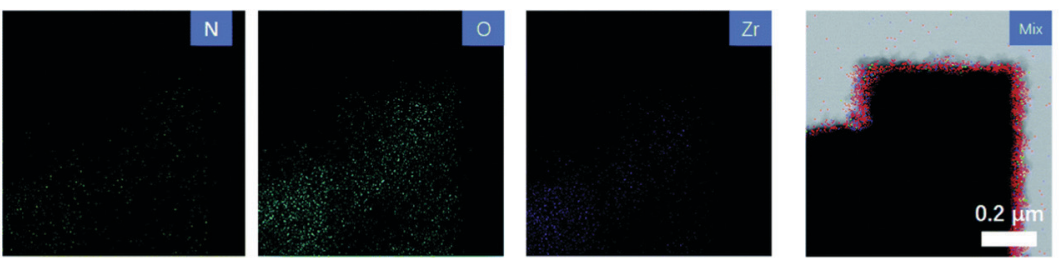

Fig. 16 (a) Schematic for the preparation of UaTDEn core-shell hetero frameworks. (b) SEM image of NH $\mathrm{H}_{2}-\mathrm{UiO}-66$; (c) SEM, (d) TEM image and (e) EDX mapping of U@TDE4. Reproduced from ref. 133 with permission from the Royal Society of Chemistry. 
(a)

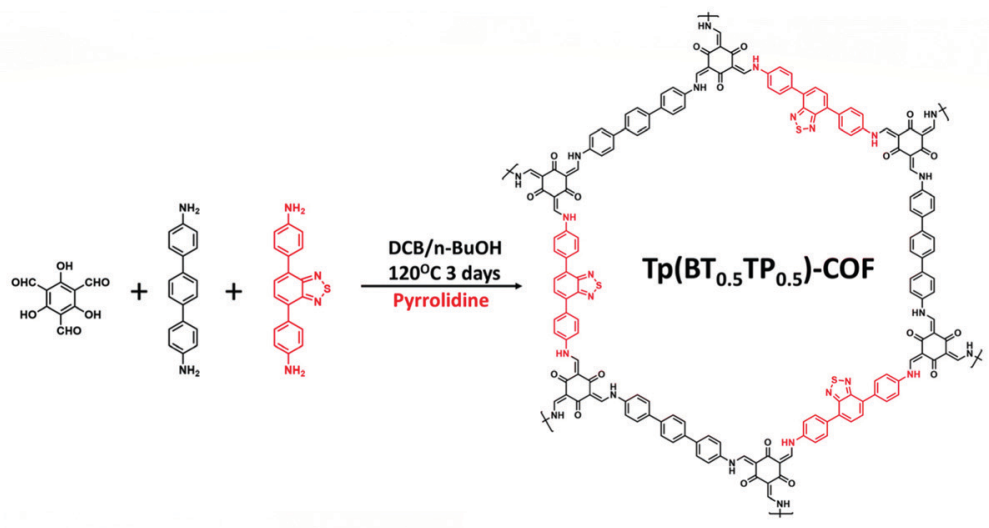

(b)

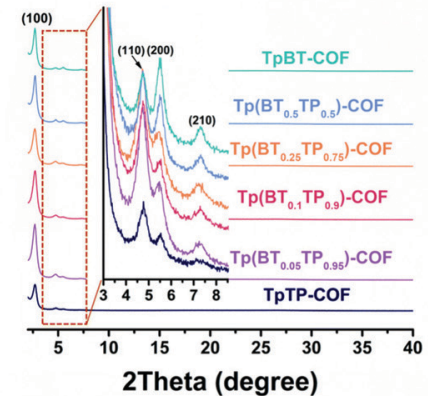

(d)

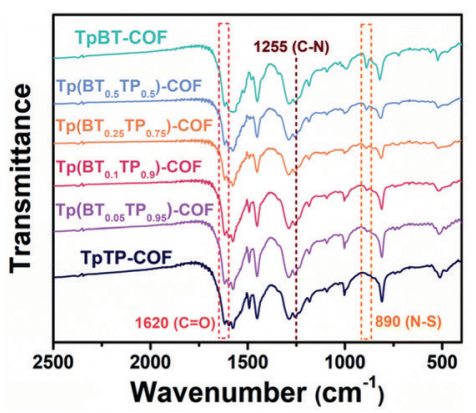

(c)

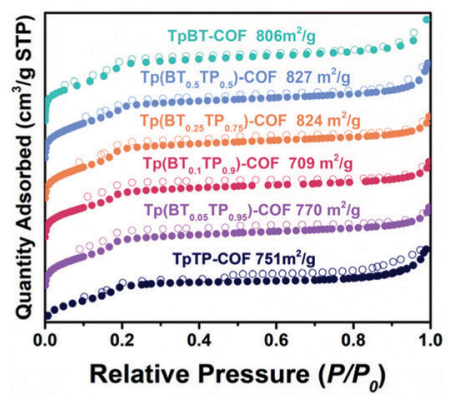

(e)

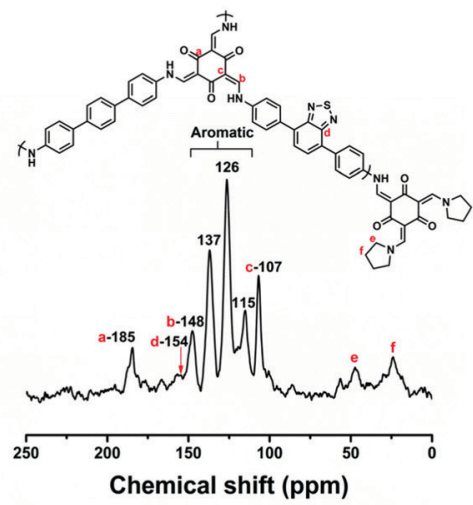

Fig. 17 Synthesis of $\mathrm{Tp}\left(\mathrm{BT}_{x} \mathrm{TP}_{1-x}\right)$-COFs. (b)-(d) PXRD, $\mathrm{N}_{2}$ adsorption-desorption and FT-IR profiles of $\mathrm{Tp}\left(\mathrm{BT} \mathrm{T}_{x} \mathrm{TP}_{1-x}\right)$-COFs. (e) Solid-state ${ }^{13} \mathrm{C}$ CP/MAS NMR spectrum of Tp(BT0.05TP 0.95 )-COF. Reproduced from ref. 134 with permission from the Royal Society of Chemistry.

their low densities, high chemical stabilities, and high thermal stabilities, making them promising candidates for use as fluorescent sensors. Often, $\pi$-conjugation of the building blocks (e.g., triazine, carbazole, pyrene, and triphenylene) or the inherently rigid structure of the COFs leads to this fluorescence behavior. We reported the first applicable COF for the detection of amino acids. We used solvothermal conditions to prepare a Cu@TFPB-DHTH COF (Fig. 18) through polycondensation of TFPB-3CHO and DHTH and subsequent modification with $\mathrm{Cu}^{2+}$ ions. $^{137}$ The BET surface area of the TFPB-DHTH COF was $360 \mathrm{~m}^{2} \mathrm{~g}^{-1}$; it displayed high thermal stability up to $322^{\circ} \mathrm{C}$. The TFPB-DHTH COF exhibited highly fluorescent yellow emission in addition to high chemical stability; the addition of $\mathrm{Cu}^{2+}$ ions quenched this fluorescence, due to aggregation. Anions had only marginal effects on this quenching. The fluorescence intensity increased upon the addition of cysteine and L-histidine. The limits of detection (LODs) for cysteine and L-histidine in the presence of the Cu@TFPB-DHTH COF were 340 and $520 \mathrm{nM}$, respectively, with high selectivity. Fluorescent COFs have also been used for the spectroscopic determination of very low concentrations (nanomolar) of $\mathrm{HCl}$. We have fabricated the three luminescent COFs BCTB-PD, BCTA-TP, and BCTB-BCTA through Schiff base condensations of BCTB-4CHO with $\mathrm{PD}, \mathrm{BCTA}-4 \mathrm{NH}_{2}$ with TP, and BCTB-4CHO with BCTA-4NH${ }_{2}$, respectively. ${ }^{138}$ The thermal stabilities of the BCTB-PD and BCTB-BCTA COFs were higher than that of the BCTA-TP COF, revealing the positive effect of BCTB$4 \mathrm{CHO}$ as the aldehydic building block. The BET surface areas of the BCTB-PD, BCTB-BCTA, and BCTA-TP COFs were 2212, 1098, and $645 \mathrm{~m}^{2} \mathrm{~g}^{-1}$, respectively. Noncovalent interactions (hydrogen bonding, dipole effects) between these COFs and polar solvents led to red-shifting upon increasing the solvent polarity, in addition to enhancing the stability of the excited states of the COFs and, hence, their corresponding intramolecular charge transfer (ICT). The BCTB-4CHO-based COFs (BCTB-PD and BCTB-BCTA) 


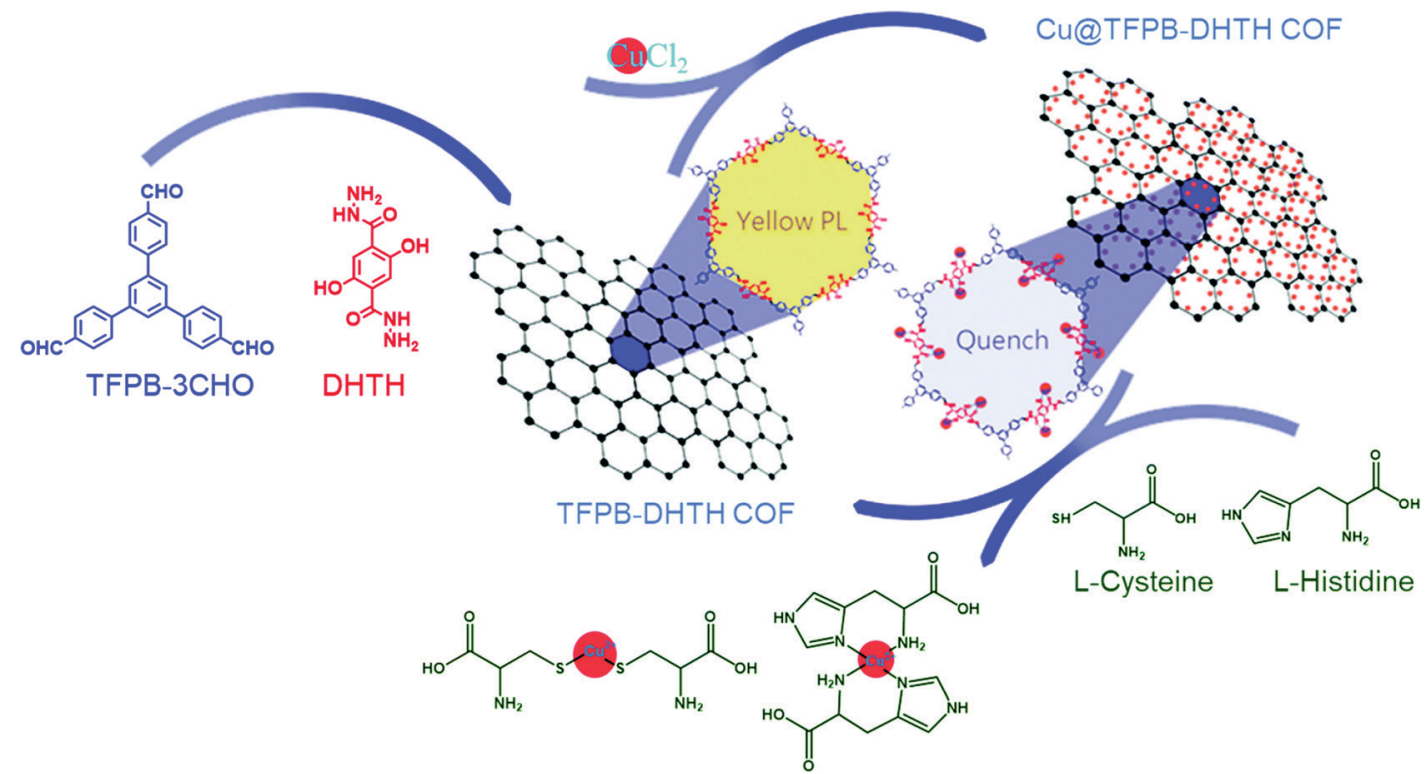

Fig. 18 Schematic representation of Cu@TFPB-DHTH COF as a chemical sensor for Cys and L-His. Reproduced from ref. 137 with permission from the Royal Society of Chemistry.

displayed fluorescence emissions because their BCTB- $4 \mathrm{CH}=\mathrm{N}$ units functioned as electron donating groups that facilitated ICT between the carbazole $\mathrm{BCTB}-4 \mathrm{CH}=\mathrm{N}$ units and the acceptors; in contrast, the weakly electron donating $\mathrm{BCTA}-4 \mathrm{~N}=\mathrm{CH}$ groups resulted in weak fluorescence for the BCTA-TP COF. The BCTB-BCTA COF displayed high fluorescence sensitivity for the detection of $\mathrm{HCl}$, due to the increasing planarity of its constituent units upon protonation of the imino nitrogen atoms in the BCTBBCTA COF architecture, resulting in red-shifting of the signal. The fluorescence lifetime of the BCTB-BCTA COF increased from 4.13 to $4.89 \mathrm{~ns}$ upon exposure to $1 \mathrm{mmol} \mathrm{L}^{-1} \mathrm{HCl}$, in addition to displaying an LOD of $10 \mathrm{nmol} \mathrm{L}^{-1}$. Increasing the planarity of the units in the COFs and converting them into quinoid structures were exploited by our group for $\mathrm{HCl}$ sensing using 2D PyTA-BC and PyTA-BC-Ph COFs, prepared through Schiff base condensations of PyTA- $4 \mathrm{NH}_{2}$ with $\mathrm{BC}-4 \mathrm{CHO}$ and $\mathrm{BC}-\mathrm{Ph}-4 \mathrm{CHO}$, respectively, and separately under solvothermal conditions. ${ }^{125}$ The PyTA-BC and PyTA-BC-Ph COFs had thermal stabilities of up to 403 and $421{ }^{\circ} \mathrm{C}$, respectively, and high surface areas (520 and $1445 \mathrm{~m}^{2} \mathrm{~g}^{-1}$, respectively); we attribute the superior thermal stability and surface area of the PyTA-BC-Ph COFs to their longer building blocks. Both the PyTA-BC and PyTA-BC-Ph COFs exhibited solvatochromism phenomena and red-shifting of their signals occurred, due to strong hydrogen bonding between the amino groups on the COF surfaces and the $\mathrm{C}=\mathrm{O}$ groups of the polar solvents, which facilitated ICT. Interactions of the PyTA-BC and PyTA-BC-Ph COFs with $\mathrm{HCl}$ also induced red-shifting from their original yellow color; the signals reverted back after exposure to $\mathrm{NH}_{3}$ vapor. This process, which could be repeated without considerable performance loss, resulted from the increase in planarity upon protonation and the formation of quinoid structures. The PyTA-BC and PyTA-BC-Ph COFs had very low LODs for $\mathrm{HCl}$ of 24 and $20 \mathrm{nmol} \mathrm{L}{ }^{-1}$, respectively. ${ }^{132}$ Guo et al. obtained a new 1D-COF with a specific surface area of $426 \mathrm{~m}^{2} \mathrm{~g}^{-1}$ and thermal stability up to $360{ }^{\circ} \mathrm{C}$ through the reaction of TFPPy and DABP; they used this COF as a chemical $\mathrm{H}^{+}$sensor in acidic solutions. $^{139} \mathrm{Zhu}$ et al. prepared a dual-luminescent COF (DL-COF) through Schiff base formation between ETTA and 9,10-anthracenedicarboxaldehyde and used it for the chemical sensing of explosive nitro compounds with high selectivity and sensitivity. ${ }^{140}$ Mohamed et al. used Heck reactions to prepare the four ultrastable microporous polymers An-HPP, TPT-HPP, Car-HPP, and TPE-HPP from octavinylsilsesquioxane (OVS) and brominated anthracene triphenyltriazine, bicarbazole, and tetraphenylethene, respectively; we revealed that these materials displayed good thermal stabilities because of the presence of the inorganic POSS units and the high crosslinking densities. ${ }^{141-144}$ Furthermore, these four fluorescent materials could be used for the detection of $\mathrm{Fe}^{3+}$ ions.

\subsection{Other applications}

Ning et al. prepared two CMPs containing organic dyes in their backbones through Sonogashira couplings of TDFB and TCT with TEB (Fig. 19). ${ }^{145}$ The TDFB-TEB CMP possessed a narrower band gap and a more planar $\pi$-conjugated structure and displayed higher photocatalytic performance towards the aerobic oxidants sulfur and amines with excellent recycling, compared with the behavior of TCT-TEF. Ma et al. reported CMP-S1, a CMP containing aromatic naphthalene moieties and a conjugated structure, that exhibited higher performance for aromatic capture than that for alkanes, based on organic vapor adsorption analysis. ${ }^{146}$ Xia et al. synthesized pTTT-BTD, pTTT-Ben, and pTTT-DMOB CMPs from 2,4,6-(tri-2-thienyl)-1,3,5-triazine as the knot block and the linkers BTD, Ben, and BMOB, respectively, each with different morphologies and electronic and optical properties. Interestingly, pTTT-Ben exhibited high 


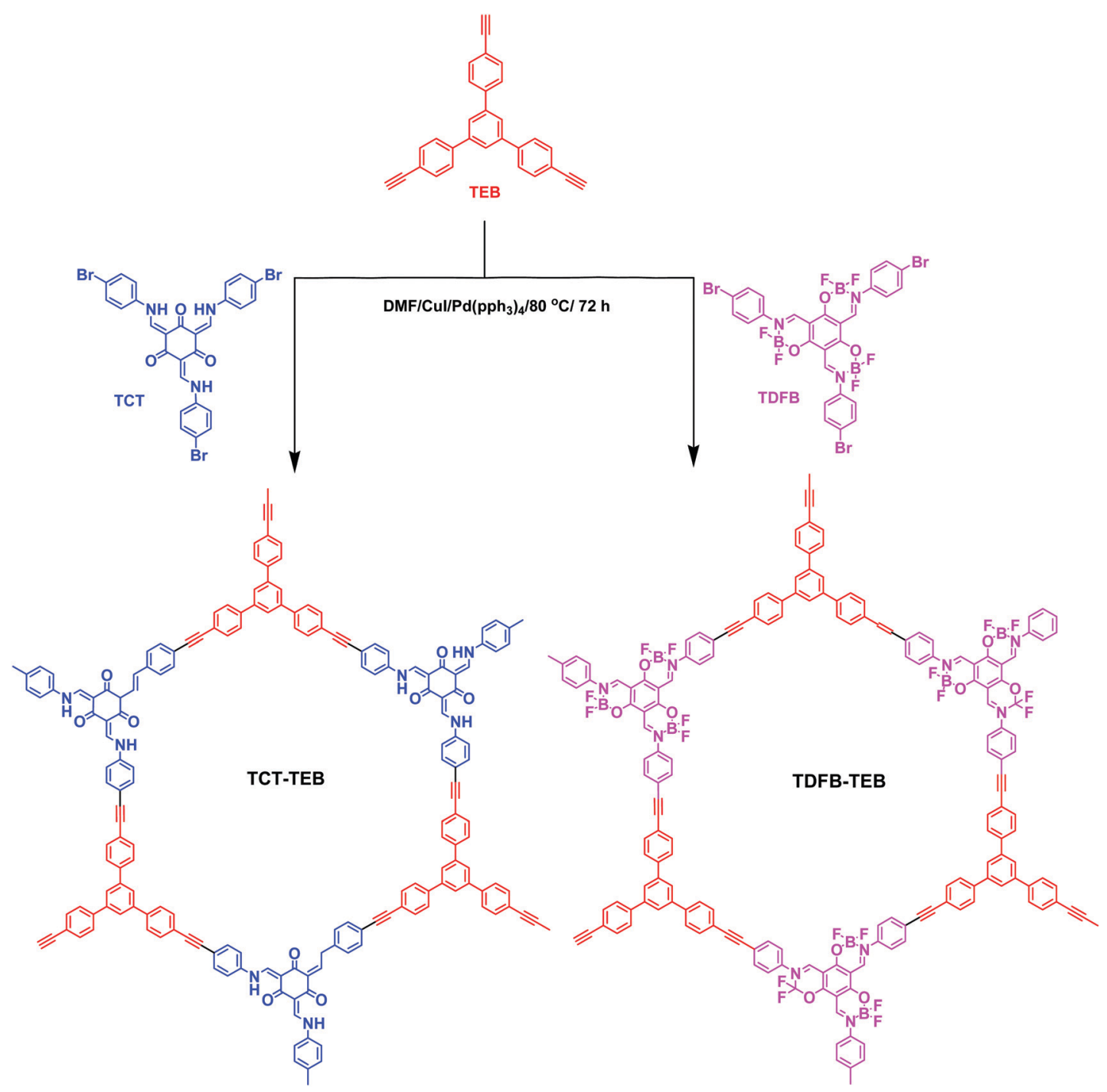

Fig. 19 Preparation of TDFB-TEB and TCT-TEB. Reproduced from ref. 145 with permission the Royal Society of Chemistry.

photocatalytic performance, providing high production rates of succinic acid (4.66 mmol $\mathrm{g}^{-1} \mathrm{~h}^{-1}$ ) and 2,5-diformylfuran (0.53 mmol g $\left.{ }^{-1} \mathrm{~h}^{-1}\right)$ from biomass materials. ${ }^{147}$ Zhang et al. incorporated phosphoric acid into porous solids through Sonogashira coupling of 1,3,5-tris(4-ethynylphenyl)benzene with various aliphatic perfluoro monomers (Fig. 20). ${ }^{148}$ The obtained electrolytes of the CMP polymers had a low activation energy $(0.4 \mathrm{eV})$ and high proton conductivity $(4.39 \times$ $10^{-3} \mathrm{~S} \mathrm{~cm}^{-1}$ ), due to their hydrophobic pores and hydrogen bonding between phosphoric acid and the perfluoroalkyl chains of the CMPs. Zhao et al. obtained the thiazolo[5,4d] thiazole-linked CMPs TZTZ-TA and TZTZ-TP through condensations of 1,3,5-tri(4-formylphenyl)benzene with 2,4,6-tri(4formylphenyl)-1,3,5-triamine (as the $\mathrm{C}_{3}$ symmetrical anode block) and with dithiooxamide (as the $\mathrm{C}_{2}$ monomer), respectively. ${ }^{149}$ The obtained CMPs had amorphous characteristics, different colors, good thermal stabilities, and BET surface areas in the range from 314.8 to $439.5 \mathrm{~m}^{2} \mathrm{~g}^{-1}$. Furthermore, the TZTZ-TA CMP containing the triazine units mediated the production of $\mathrm{NADH}(82.0 \mathrm{wt} \%$ within $5 \mathrm{~min})$ to an outstanding degree when compared with that of TZTZ-TP (6.9 wt $\%$ during $10 \mathrm{~min}$ ). Lang et al. prepared a different series of CMPs, based on fluorene and carbazole units as electron donating groups, and observed that MFC-CMP displayed a high BET specific surface area, more sites for oxidation, and good performance in the production of imines and oxygen through amine oxidation under visible light photocatalysis. ${ }^{150}$ Hua and co-workers used Sonogashira coupling to prepare a series of fluorescent $\mathrm{CMPH}, \mathrm{CMPNH}_{2}$, and CMPN materials containing amino groups. CMPN, which featured $N, N$-diethylpropylamine units as side chains in the framework, exhibited good $\mathrm{I}_{2}$ capacity and excellent stability towards $\beta$ - and $\gamma$-ray irradiation, which was the result of the formation of charge-transfer complexes between $\mathrm{I}_{2}$ and the amino, phenyl, and triazine groups. ${ }^{151}$ Maji et al. constructed a CMP containing dithienyl units as photochromic groups through Schiff-base condensation of dithienylethene aldehyde and benzene-1,3,5-tricarboxyhydrazide [Fig. 21(a)]. ${ }^{152}$ They investigated its porosity, chemical structure, morphology, and 


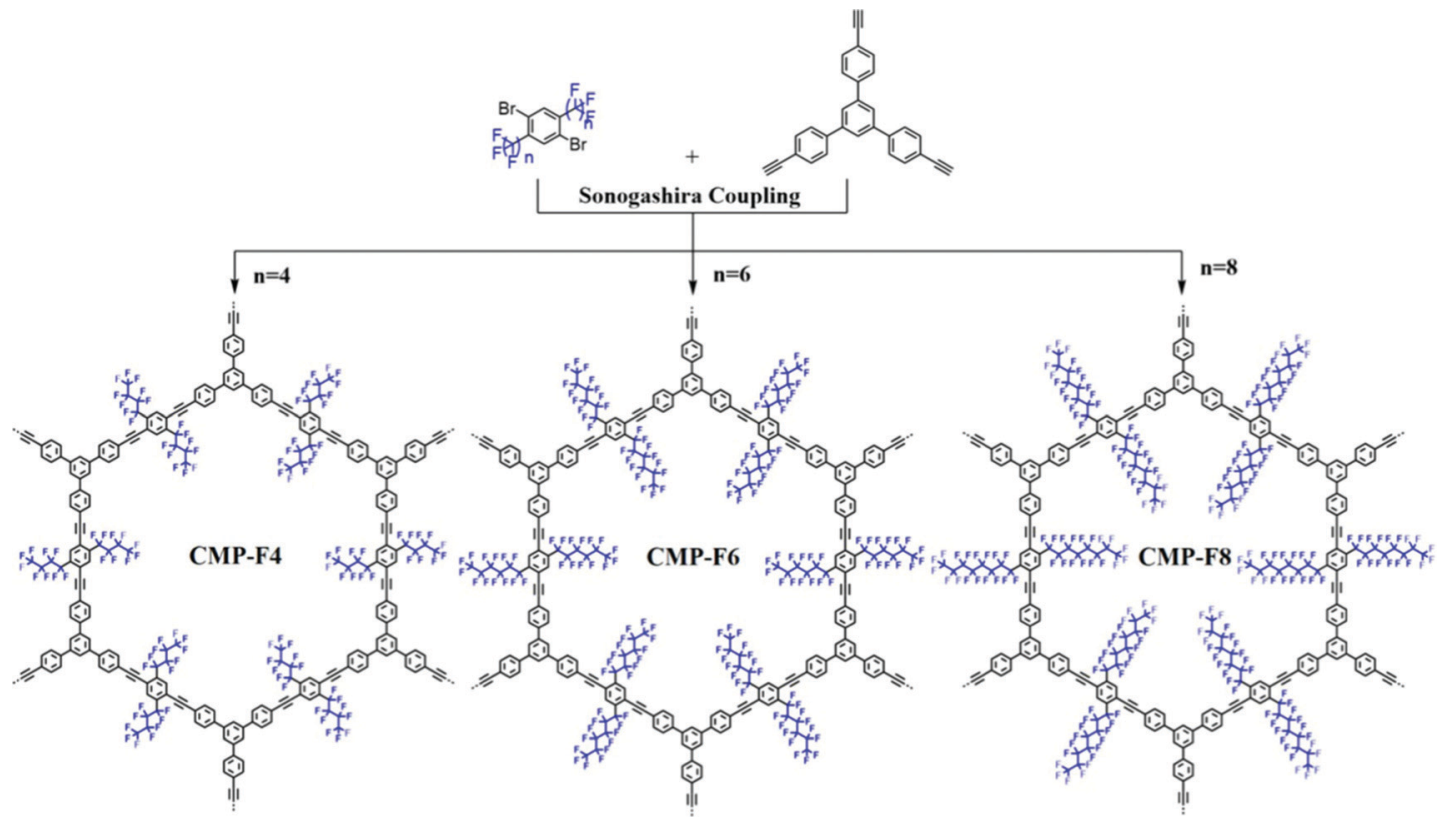

Fig. 20 Synthesis of perfluoroalkyl-functionalized CMPs. Reproduced from ref. 148 with permission from American Chemical Society.
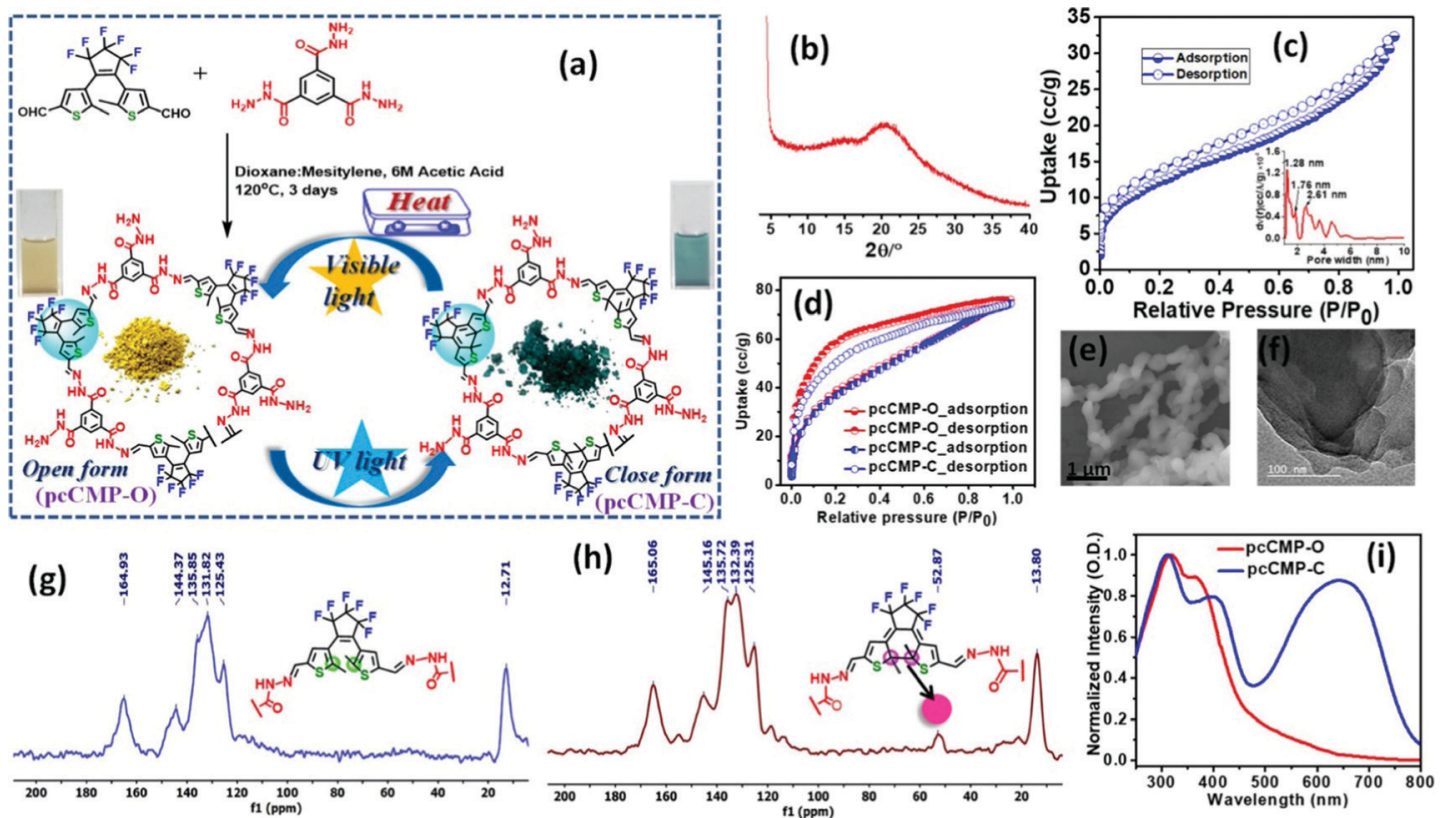

Fig. 21 (a) Preparation of the pcCMP (b) PXRD for pcCMP-O; (c) $\mathrm{N}_{2}$ adsorption (77 K) for pcCMP-O; (d) $\mathrm{CO}_{2}$ adsorption for pcCMP-O and pcCMP-C; (e) FESEM and (f) TEM images for pcCMPO; ( $g$ and $\mathrm{h}$ ) solid-state ${ }^{13} \mathrm{C}$ NMR for pcCMP-O and pcCMP-C, respectively; and (i) UV-vis absorption spectra in the solid state for PCCMP-O and PCCMP-C. Reproduced from ref. 152 with permission from American Chemical Society.

optical and crystallinity properties [Fig. 21(e)-(t)]. The pcCMP-O structure had a yellow color that, after UV irradiation, changed to give the deep-green pcCMP-C; in addition, pcCMP-O functioned as an $\mathrm{NH}$ function logic gate. $\mathrm{Li}$ and co-workers prepared a metal-free heterogeneous catalyst (2,5-DCP-CTF) through the cyclotrimerization of 2,5-dicyanopyridine in the presence of molten $\mathrm{ZnCl}_{2}{ }^{153}$ 2,5-DCP-CTF possessed a high nitrogen atom content and a hierarchical porous structure; they used it for the preparation of cyclic carbonates with high selectivity and for the conversion of $\mathrm{CO}_{2}$. Hu et al. used silicon-promoted cationic polymerization to synthesize a series of HCPs with outstanding chemical stability, surface area, tunable porosity, and extended conjugation, which were capable of capturing dibenzothiophene $\left(1335 \mathrm{mg} \mathrm{g}^{-1}\right) \cdot{ }^{154}$ Hou et al. prepared TFPPy-Td-COFs with a high surface area $\left(1094 \mathrm{~m}^{2} \mathrm{~g}^{-1}\right)$ and uniform pore size $(2.87 \mathrm{~nm})$ through the condensation of TFPPy with thiadiazole- $2 \mathrm{HN}_{2} \cdot{ }^{155}$ 


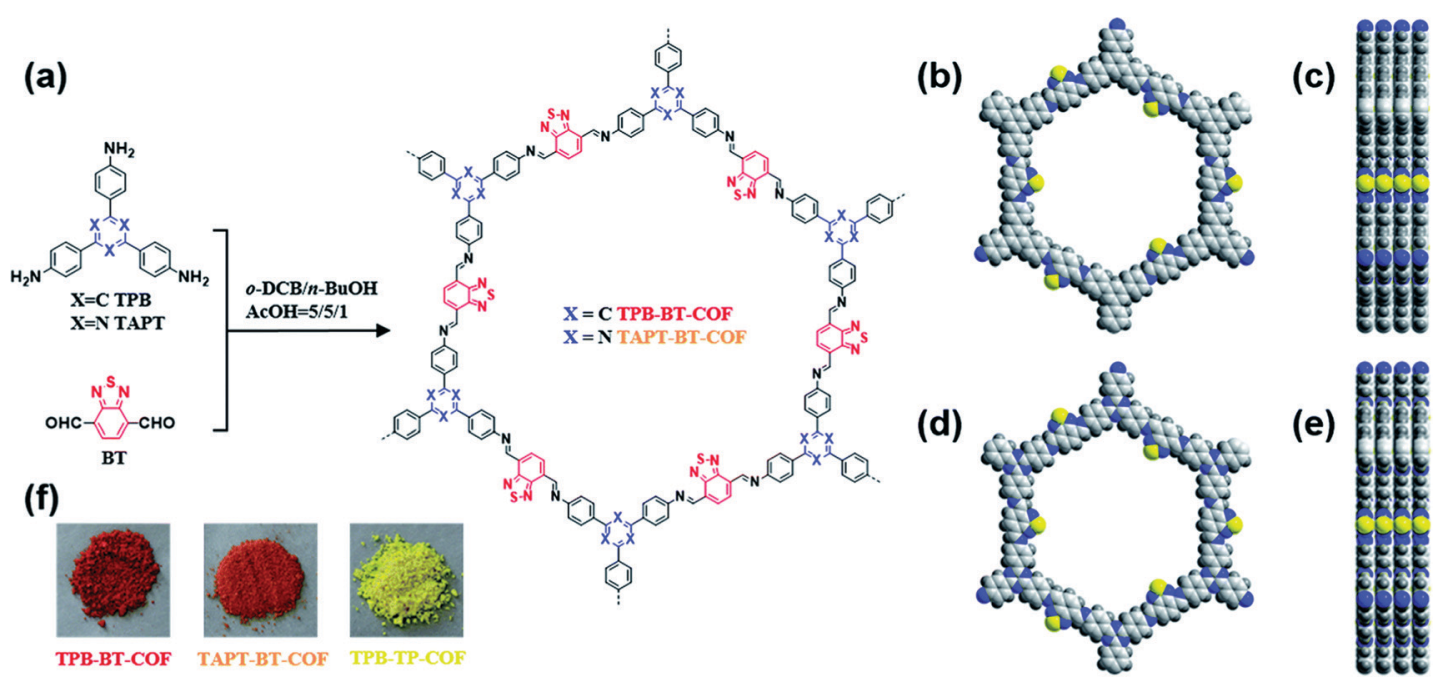

Fig. 22 (a) Synthesis of BT-COFs; (b) top and (c) side view of TPB-BT-COF; (d) top and (e) side view of TAPT-BT-COF; (f) photographs of TPB-BT-COF, TAPT-BT-COF and TPB-TP-COF. Reproduced from ref. 156 with permission from the Royal Society of Chemistry.

Interestingly, they prepared polymethylacrylates with a narrow polydispersity index when using TFPPy-Td-COFs as a heterogeneous photocatalyst for atom transfer radical polymerization (ATRP) photo-induced polymerization under irradiation with white light in the presence of $\mathrm{Cu}(\mathrm{I})$. In 2019, Chen et al. prepared two kinds of donor-acceptor 2D-COFs (TPB-BT-COF, and TAPTBT-COF), featuring benzothiadiazole (BT) units as electron acceptors, through condensation reactions (Fig. 22). ${ }^{156}$ These materials possessed outstanding porosities, were chemically stable under strongly acidic and basic conditions, and had high crystallinities. The rate of photoreduction of an aqueous solution of hexavalent chromium $[\mathrm{Cr}(\mathrm{vI})]$ in the presence of the TPB-BT-COF was faster than that in the presence of the TAPT-BT-COF, due to the former having a narrower band gap and an abundant negative conduction band, allowing facile migration and separation of hole pairs/photogenerated electrons. In 2020, Jiang et al. synthesized the $\mathrm{sp}^{2}-\mathrm{N}$ enriched TM-TPT-COF through the reaction of TM with TPT in the presence of a basic catalyst. ${ }^{157}$ They then prepared Pt@COF through the reaction of the TM-TPT-COF with $\mathrm{K}_{2} \mathrm{PtCl}_{4}$; the presence of Pt NPs in the COF layers was confirmed using high-resolution TEM (HR-TEM), X-ray photoelectron spectroscopy (XPS), X-ray absorption spectroscopy, and WT-extended XAFS (EXAFS). The ORR mediated by the fabricated Pt@COF electrocatalyst in an acidic electrolyte was superior to that of a commercial Pt/C catalyst. In 2020, Huang et al. constructed a 2D-COF based on porphyrin units (TAPP-TFPP-COF) from the reaction of TAPP with TFPP; it exhibited excellent crystallinity, stability, tetragonal micropores, a high BET surface area of $962 \mathrm{~m}^{2} \mathrm{~g}^{-1}$ and a pore size of $1.8 \mathrm{~nm}$ (Fig. 23). ${ }^{158}$ The conductivity of the TAPP-TFPP-COF after doping with $\mathrm{I}_{2}$ increased from $1.12 \times 10^{-10}$

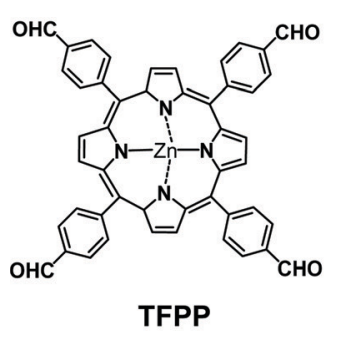

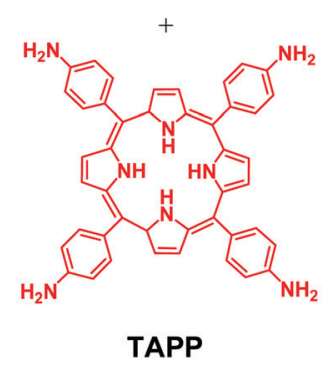

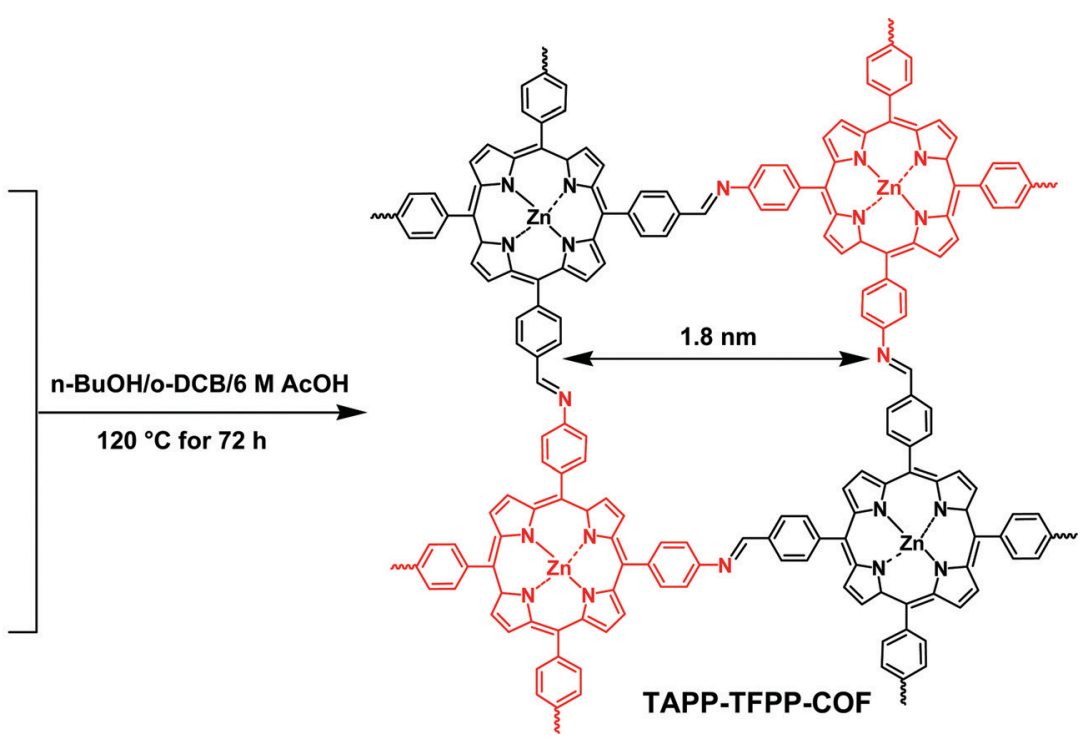

Fig. 23 Synthesis of microporous TAPP-TFPP-COF. Reproduced from ref. 158 with permission from American Chemical Society. 
to $1.46 \times 10^{-7} \mathrm{~S} \mathrm{~cm}^{-1}$; furthermore, TAPP-TFPP-COF films displayed high sensitivity and selectivity at $700 \mathrm{~nm}$, based on spectroscopic detection. Our group contributed to the development of perovskite solar cells through the preparation of the 2D-COFs Car-ETTA and TFPPy-ETTA through [4+4] solvothermal condensations of ETTA with Car-4CHO and TFPPy, respectively. The Car-ETTA and TFPPy-ETTA COFs possessed high thermal stabilities (up to 467 and $580{ }^{\circ} \mathrm{C}$, respectively) and high surface areas (829 and $1156 \mathrm{~m}^{2} \mathrm{~g}^{-1}$, respectively). Perovskite solar cells modified with the Car-ETTA and TFPPy-ETTA COFs displayed high power conversion efficiencies (PCEs), up to 19.79 and $19.72 \%$, respectively, resulting from minimized charge recombination at the perovskite-PTAA-COF interfaces, due to low energy levels of the highest occupied molecular orbitals of the COFs. ${ }^{159}$

\section{Conclusion and Outlook}

POPs, including CTFs, COFs, HCPs, and CMPs, are attractive porous materials, and are comparable with metal-organic framework inorganic zeolites, because they possess excellent chemical and thermal stabilities, low densities, and tunable porosities, while being easy to prepare with flexible designs and structural diversity. These porous materials have been applied as useful platforms in many fields, including energy storage and conversion, gas separation, chemical sensing, luminescence, electronic devices, drug delivery, and $\mathrm{H}_{2}$ evolution from water. In this review, we discuss many examples of recent progress in the preparation of these materials, as well as the excellent performance of some POPs applied for $\mathrm{CO}_{2}$ uptake, energy storage, $\mathrm{H}_{2}$ evolution, photocatalysis, and photovoltaics. In the past few years, many research groups have prepared such materials with excellent properties; nevertheless, the use of novel synthetic methods for the preparation of new CMPs, CTFs, and COF remains worthwhile. For example, even COF materials with Frank-Kasper phases or Archimedean tiling patterns could have specific applications, and are interesting to consider. Finally, further exploration of the properties and applications of new POP materials will continue to open doors in both academia and industry.

\section{Author contributions}

The manuscript was written through contributions from all authors.

\section{Abbreviation}

$\begin{array}{ll}\text { An } & \text { Anthracene } \\ \text { BTD } & \text { Benzothiadiazole } \\ \text { Ben } & \text { Benzene } \\ \text { BD } & \text { Benzidine } \\ \text { BT } & \text { Benzothiadiazole } \\ \text { Cz-4CHO } & \text { Bi-carbazole-4CHO } \\ \text { Car-4CN } & {\left[9,9^{\prime} \text {-Bicarbazole }\right]-3,3^{\prime}, 6,6^{\prime} \text {-tetracarbonitrile }}\end{array}$

An-4Ph

BFTB-4CHO

BFTB- $4 \mathrm{NH}_{2}$

BCTA- $4 \mathrm{NH}_{2}$

BCTB- $4 \mathrm{CHO}$

BC-Ph-4CHO

TCNPy

$\mathrm{CO}_{2}$

OVS

CTFs

COFs

CMPs

DHBD

DAHQ-2HCl

$\mathrm{DHTH}$

BMOB

DABP

$\gamma$-CD

ETTA

$\mathrm{H}_{2}$

$\mathrm{H}_{2} \mathrm{O}_{2}$

HCPs

htb

hxl

kgm

IUPAC

ICT

$\mathrm{Li}-\mathrm{S}$

$\mathrm{LiOH}$

MOFs

NTCDA

PS

Py

POPs

PAFS

PIMs

PMDA

PA

PDA

PD

PyTA-4NH PyTA-4NH SEM

TEM

TGA

$\mathrm{TfOH}$

Car- $3 \mathrm{NH}_{2}$
9,10-Bis(diphenylmethylene)-9,10-

dihydroanthracene

$4,4^{\prime}, 4^{\prime \prime}, 4^{\prime \prime \prime}$-([9,9'-Bifluorenylidene $]-3,3^{\prime}, 6,6^{\prime}$ -

tetrayl) tetrabenzaldehyde

$4,4^{\prime}, 4^{\prime \prime}, 4^{\prime \prime \prime}$-([9,9'-Bifluorenylidene $]-3,3^{\prime}, 6,6^{\prime}$ tetrayl)tetraaniline

$4,4^{\prime}, 4^{\prime \prime}, 4^{\prime \prime \prime}-\left(\left[9,9^{\prime}\right.\right.$-Bicarbazole $]-3,3^{\prime}, 6,6^{\prime}$ -

tetrayl)tetraaniline

$4,4^{\prime}, 4^{\prime \prime}, 4^{\prime \prime \prime}-\left(\left[9,9^{\prime}\right.\right.$-Bicarbazole $]-3,3^{\prime}, 6,6^{\prime}$ -

tetrayl)tetrabenzaldehyde

$4,4^{\prime}, 4^{\prime \prime}, 4^{\prime \prime \prime}-\left(\left[9,9^{\prime}\right.\right.$-Bicarbazole $]-3,3^{\prime \prime}, 6,6^{\prime \prime}$ -

tetrayl)tetrabenzaldehyde

1,3,6,8-Cyanopyrene

Carbon dioxide

Cubic octavinylsilsesquioxane

Covalent triazine frameworks

Covalent organic frameworks

Conjugated microporous polymers

3,3'-Dihydroxybenzidine

2,5-Diaminohydroquinone dihydrochloride

2,5-Dihydroxyterephthalohydrazide

Dimethoxybenzene

4,4'-Diaminobenzophenone

$\gamma$-Cyclodextrin

$4,4^{\prime}, 4^{\prime \prime}, 4^{\prime \prime \prime}$-(Ethane-1,1,2,2-tetrayl)tetranilino

Hydrogen

Hydrogen peroxide

Hypercrosslinked polymers

Hexagonal tungsten bronze

Hexagonal layer

Kagome

International Union of Pure and Applied

Chemistry

Intramolecular charge transfer

Lithium-sulfur batteries

Lithium hydroxide

Metal-organic frameworks

1,4,5,8-Naphthalenetetracarboxylic

dianhydride

Polystyrene

Pyrene

Porous organic polymers

Porous aromatic frameworks

Polymers of intrinsic microporosity

Pyromellitic dianhydride

Phenylamine

Phenylenediamine

p-Phenylenediamine

$4,4^{\prime}, 4^{\prime \prime}, 4^{\prime \prime \prime}$-(Pyrene-1,3,6,8-tetrayl)tetraaniline

$4,4^{\prime}, 4^{\prime \prime}, 4^{\prime \prime \prime}$-Pyrene-1,3,6,8-tetrayl)tetraaniline

Scanning electron microscope

Transmission electron microscope

Thermogravimetry analyses

Trifluoromethanesulfonic acid

Triamine 9-(4-aminophenyl)-carbazole-3,6-

diamine 


\begin{tabular}{|c|c|}
\hline TPA-3CHO & Tris(4-formylphenyl)amine \\
\hline TPP-3CHO & 2,4,6-Tris(4-formylphenyl)pyridine \\
\hline TPT-3СHO & 2,4,6-Tris(4-formylphenyl)triazine \\
\hline TPA-3NH ${ }_{2}$ & Tris(4-aminophenyl)amine \\
\hline TPT- $3 \mathrm{NH}_{2}$ & 2,4,6-Tris(4-aminophenyl)triazine \\
\hline TFP-3OHCHO & 1,3,5-Triformylphloroglucinol \\
\hline TAPA & Tris(4-aminophenyl)amine \\
\hline TAPB & 1,3,5-Tris(4-aminophenyl)benzene \\
\hline $\operatorname{TPPDA}\left(\mathrm{NH}_{2}\right)_{4}$ & Tetraphenyl-p-phenylenediamine \\
\hline TPPyr $(\mathrm{CHO})_{4}$ & 1,3,6,8-Tetrakis(4-formylphenyl)pyrene \\
\hline TPTPE $(\mathrm{CHO})_{4}$ & $\begin{array}{l}\text { 1,1,2,2-Tetrakis[4-formyl-(1,1'- } \\
\text { biphenyl)]ethane) }\end{array}$ \\
\hline TBN & Tetrabenzonaphthalene \\
\hline $\mathrm{Tp}$ & 1,3,5-Triformylphloroglucinol \\
\hline TPE & Tetraphenylethene \\
\hline Pyr-4Ph & Tetraphenylpyrazine \\
\hline TNT & Trinitrotoluene \\
\hline TFPB-3CHO & 1,3,5-Tris(4-formylphenyl)benzene \\
\hline BC- $4 \mathrm{CHO}$ & $3,3^{\prime}, 6,6^{\prime \prime}$-Tetraformyl-9,9" $9^{\prime \prime}$-bicarbazole \\
\hline TFPPy & 1,3,6,8-Tetrakis( $p$-formylphenyl)pyrene \\
\hline $\mathrm{TP}$ & Terephthalaldehyde \\
\hline TPT & Triphenyltriazine \\
\hline Ben-T & 1,3,5-Tris(4-ethynylphenyl)benzene \\
\hline TM & 2,4,6-Trimethyl-1,3,5-trizaine \\
\hline Car- $4 \mathrm{CHO}$ & $3,3^{\prime}, 6,6^{\prime}$-Tetraformyl-9,9'-bicarbazole \\
\hline $\mathrm{B}(\mathrm{OMe})_{3}$ & Trimethyl borate \\
\hline sql & Square lattice \\
\hline SBUs & Secondary building units \\
\hline SWCNTs & Single walled carbon nanotubes \\
\hline TAPP & Zinc 5,10,15,20-tetra(4-aminophenyl)porphyrin \\
\hline FPP & Zinc 5,10,15,20-tetra(4-formylphenyl)porphyrin \\
\hline
\end{tabular}

\section{Conflicts of interest}

The authors declare that they have no conflicts of interest.

\section{Acknowledgements}

This study was supported financially by the Ministry of Science and Technology, Taiwan, under contracts MOST 106-2221E-110-067-MY3，108-2638-E-002-003-MY2，108-2218-E-110-013MY3, and 108-2221-E-110-014-MY3.

\section{References}

1 J. S. M. Lee and A. I. Cooper, Advances in Conjugated Microporous Polymers, Chem. Rev., 2020, 120, 2171-2214.

2 Y. Z. Cheng, X. Ding and B. H. Han, Porous Organic Polymers for Photocatalytic Carbon Dioxide Reduction, ChemPhotoChem, 2021, 5, 406-417.

3 T. X. Wang, H. P. Liang, D. A. Anito, X. Ding and B. H. Han, Emerging applications of porous organic polymers in visible-light photocatalysis, J. Mater. Chem. A, 2020, 8, 7003.
4 K. Amin, N. Ashraf, L. Mao, C. F. J. Faul and Z. Wei, Conjugated microporous polymers for energy storage: Recent progress and challenges, Nano Energy, 2021, 85, 105958.

5 M. G. Mohamed, M. Y. Tsai, W. C. Su, A. F. M. EL-Mahdy, C. F. Wang, C. F. Huang, L. Dai, T. Chen and S. W. Kuo, Nitrogen-Doped microporous carbons derived from azobenzene and nitrile-functionalized polybenzoxazines for $\mathrm{CO}_{2}$ uptake, Mater. Today Commun., 2020, 24, 101111.

6 M. G. Mohamed, S. M. Ebrahium, A. S. Hammam, S. W. Kuo and K. I. Aly, Enhanced $\mathrm{CO}_{2}$ capture in nitrogenenriched microporous carbons derived from Polybenzoxazines containing azobenzene and carboxylic acid units, J. Polym. Res., 2020, 27, 197.

7 S. Wang, C. Zhang, Y. Shu, S. Jiang, Q. Xia, L. Chen, S. Jin, I. Hussain, A. I. Cooper and B. Tan, Layered Microporous Polymers by Solvent Knitting Method, Sci. Adv., 2017, 3, e1602610.

8 M. M. Samy, G. Mohamed, T. H. Mansoure, T. S. Meng, M. A. R. Khan, C. C. Liaw and S. W. Kuo, Solid state chemical transformations through ring-opening polymerization of ferrocene-based conjugated microporous polymers in host-guest complexes with benzoxazine-linked cyclodextrin, J. Taiwan Inst. Chem. Eng., 2021, DOI: 10.1016/j.jtice.2021.10.010.

9 M. G. Mohamed, M. H. Elsayed, A. M. Elewa, A. F. M. ELMahdy, C. H. Yang, A. A. K. Mohammed, H. H. Chou and S. W. Kuo, Pyrene-containing conjugated organic microporous polymers for photocatalytic hydrogen evolution from water, Catal. Sci. Technol., 2021, 11, 2229-2241.

10 X. Li, C. Zhang, S. Cai, X. Lei, V. Altoe, F. Hong, J. J. Urban, J. Ciston, E. M. Chan and Y. Liu, Facile transformation of imine covalent organic frameworks into ultrastable crystalline porous aromatic frameworks, Nat. Commun., 2018, 9, 2998.

11 M. G. Mohamed, W. C. Chen, A. F. M. El-Mahdy and S. W. Kuo, Porous organic/inorganic polymers based on double-decker silsesquioxane for high-performance energy storage, J. Polym. Res., 2021, 28, 219.

12 M. M. Samy, M. G. Mohamed and S. W. Kuo, Directly synthesized nitrogen-and-oxygen-doped microporous carbons derived from a bio-derived polybenzoxazine exhibiting high-performance supercapacitance and $\mathrm{CO}_{2}$ uptake., Eur. Polym. J., 2020, 138, 109954.

13 A. F. M. EL-Mahdy, T. C. Yu, M. G. Mohamed and S. W. Kuo, Secondary Structures of Polypeptide-Based Diblock Copolymers Influence the Microphase Separation of Templates for the Fabrication of Microporous Carbons, Macromolecules, 2021, 54, 1030-1042.

14 J. Y. Wu, M. G. Mohamed and S. W. Kuo, Directly synthesized nitrogen-doped microporous carbons from polybenzoxazine resins for carbon dioxide capture, Polym. Chem., 2017, 8, 5481-5489.

15 M. Thommes, K. Kaneko, A. V. Neimark, J. P. Olivier, F. Rodriguez-Reinoso, J. Rouquerol and K. S. W. Sing, Physisorption of Gases, with Special Reference to the 
Evaluation of Surface Area and Pore Size Distribution (IUPAC Technical Report), Pure Appl. Chem., 2015, 87, 1051.

16 J. Wei, Z. Sun, W. Luo, Y. Li, A. A. Elzatahry, A. M. Al-Enizi, Y. Deng and D. Zhao, New Insight into the Synthesis of Large-Pore Ordered Mesoporous Materials, J. Am. Chem. Soc., 2017, 139, 1706-1713.

17 X. Y. Yang, L. H. Chen, J. C. Rooke and C. Sanchez, Hierarchically porous materials: synthesis strategies and structure design, Chem. Soc. Rev., 2017, 46, 481-558.

18 K. I. Aly, M. M. Sayed, M. G. Mohamed, S. W. Kuo and O. Younis, A facile synthetic route and dual function of network luminescent porous polyester and copolyester containing porphyrin moiety for metal ions sensor and dyes adsorption, Microporous Mesoporous Mater., 2020, 298, 110063.

19 M. G. Mohamed, E. C. Atayde Jr, B. M. Matsagard, J. Nag, Y. Yamauchi, K. C. W. Wu and S. W. Kuo, Construction Hierarchically Mesoporous/Microporous Materials Based on Block Copolymer and Covalent Organic Framework, J. Taiwan Inst. Chem. Eng., 2020, 112, 180-192.

20 W. S. Hung, M. M. M. Ahmed, M. G. Mohamed and S. W. Kuo, Competing hydrogen bonding produces mesoporous/macroporous carbons templated by a highmolecular-weight poly(caprolactone- $b$-ethylene oxide- $b$ caprolactone) triblock copolymer, J. Polym. Res., 2020, $27,173$.

21 J. G. Li, P. Y. Lee, M. M. M. Ahmed, M. G. Mohamed and S. W. Kuo, Varying the Hydrogen Bonding Strength in Phenolic/PEO- $b$-PLA Blends Provides Mesoporous Carbons Having Large Accessible Pores Suitable for Energy Storage, Macromol. Chem. Phys., 2020, 221, 2000040.

22 W. Li, Q. Yue, Y. Deng and D. Zhao, Ordered Mesoporous Materials Based on Interfacial Assembly and Engineering, Adv. Mater., 2013, 25, 5129-5152.

23 M. O'Keeffe, Design of MOFs and Intellectual Content in Reticular Chemistry: A Personal View, Chem. Soc. Rev., 2009, 38, 1215-1217.

24 H. Furukawa, K. E. Cordova, M. O’Keeffe and O. M. Yaghi, The Chemistry and Applications of Metal-Organic Frameworks, Science, 2013, 341, 1230444.

25 L. Li, M. Zhang, R. Li, H. Jiang and Z. Liu, Facile synthesis of highly luminescent rod-like terbium-based metalorganic frameworks for sensitive detection of olaquindox, Anal. Methods, 2021, 13, 3785-3791.

26 T. Ben and S. Qiu, Porous Aromatic Frameworks: Synthesis, Structure and Functions, CrystEngComm, 2013, 15, 17-26.

27 Y. Xu, S. Jin, H. Xu, A. Nagai and D. Jiang, Conjugated Microporous Polymers: Design, Synthesis and Application, Chem. Soc. Rev., 2013, 42, 8012-8031.

28 T. Hasell and A. I. Cooper, Porous Organic Cages: Soluble, Modular and Molecular Pores, Nat. Rev. Mater., 2016, 1, 16053.

29 A. P. Côté, A. I. Benin, N. W. Ockwig, M. Keeffe, A. J. Matzger and O. M. Yaghi, Porous, Crystalline, Covalent Organic Frameworks, Science, 2005, 310, 1166-1170.
30 P. Katekomol, J. Roeser, M. Bojdys, J. Weber and A. Thomas, Covalent Triazine Frameworks Prepared from 1,3,5-Tricyanobenzene, Chem. Mater., 2013, 25, 1542-1548.

31 J.-X. Jiang, F. Su, A. Trewin, C. D. Wood, N. L. Campbell, H. Niu, C. Dickinson, A. Y. Ganin, M. J. Rosseinsky, Y. Z. Khimyak and A. I. Cooper, Angew. Chem., Int. Ed., 2007, 46, 8574-8578.

32 S. Xu, Y. Luo and B. Tan, Recent Development of Hypercrosslinked Microporous Organic Polymers, Macromol. Rapid Commun., 2013, 34, 471-484.

33 K. Konstas, J. W. Taylor, A. W. Thornton, C. M. Doherty, W. X. Lim, T. J. Bastow, D. F. Kennedy, C. D. Wood, B. J. Cox, J. M. Hill, A. J. Hill and M. R. Hill, Lithiated Porous Aromatic Frameworks with Exceptional Gas Storage Capacity, Angew. Chem., Int. Ed., 2012, 51, 6639-6642.

34 A. M. Elewa, A. F. M. EL-Mahdy, M. H. Elsayed, M. G. Mohamed, S. W. Kuo and H. H. Chou, Sulfur-doped triazine-conjugated microporous polymers for achieving the robust visible-light-driven hydrogen evolution, Chem. Eng. J., 2021, 421, 129825.

35 X. Gao, C. Shu, C. Zhang, W. Ma, S. B. Ren, F. Wang, Y. Chen, J. H. Zeng and J. X. Jiang, Substituent effect of conjugated microporous polymers on the photocatalytic hydrogen evolution activity, J. Mater. Chem. A, 2020, 8, 2404-2411.

36 Y. Xu, N. Mao, S. Feng, C. Zhang, F. Wang, Y. Chen, J. Zeng and J. X. Jiang, Perylene-containing conjugated microporous polymers for photocatalytic hydrogen evolution, Macromol. Chem. Phys., 2017, 218, 1700049.

37 G. Gatti, M. Errahali, L. Tei, M. Cossi and L. Marchese, On the Gas Storage Properties of 3D Porous Carbons Derived from Hyper-Crosslinked Polymers, Polymers, 2019, 11, 588.

38 M. Liu, L. Guo, S. Jin and B. Tan, Covalent triazine frameworks: synthesis and applications, J. Mater. Chem. A, 2019, 7, 5153-5172.

39 S. Das, P. Heasman, T. Ben and S. Qiu, Porous organic materials: strategic design and structure-function correlation, Chem. Rev., 2017, 117, 1515-1563.

40 N. B. McKeown, The synthesis of polymers of intrinsic microporosity (PIMs), Sci. China: Chem., 2017, 60, 1023-1032.

41 S. J. Yang, X. Ding and B. H. Han, Conjugated microporous polymers with extended p-structures for organic vapor adsorption, Macromolecules, 2018, 51, 947-953.

42 C. Dai and B. Liu, Conjugated polymers for visible-light driven photocatalysis, Energy Environ. Sci., 2020, 13, 24-52.

43 J. Byun and K. A. I. Zhang, Designing conjugated porous polymers for visible light-driven photocatalytic chemical transformations, Mater. Horiz., 2020, 7, 15-31.

44 T. Zhang, G. Xing, W. Chen and L. Chen, Porous organic polymers: a promising platform for efficient photocatalysis, Mater. Chem. Front., 2020, 4, 332-353.

45 W. Liu, X. Li, C. Wang, H. Pan, W. Liu, K. Wang, Q. Zeng, R. Wang and J. Jiang, A scalable general synthetic approach toward ultrathin imine-linked two-dimensional covalent organic framework nanosheets for photocatalytic $\mathrm{CO}_{2}$ reduction, J. Am. Chem. Soc., 2019, 141, 17431-17440. 
46 Y. Yuan and G. Zhu, Porous aromatic frameworks as a platform for multifunctional applications, ACS Cent. Sci., 2019, 5, 409-418.

$47 \mathrm{H}$. Urakami, K. Zhang and F. Vilela, Modification of conjugated microporous poly-benzothiadiazole for photosensitized singlet oxygen generation in water, Chem. Commun., 2013, 49, 2353-2355.

48 W. Ma, Q. Zheng, Y. He, G. Li, W. Guo, Z. Lin and L. Zhang, Size-controllable synthesis of uniform spherical covalent organic frameworks at room temperature for highly efficient and selective enrichment of hydrophobic peptides, J. Am. Chem. Soc., 2019, 141, 18271-18277.

49 R. Xu, X. S. Wang, H. Zhao, H. Lin, Y. B. Huang and R. Cao, Rhenium-modified porous covalent triazine framework for highly efficient photocatalytic carbon dioxide reduction in a solid-gas system, Catal. Sci. Technol., 2018, 8, 2224-2230.

50 L. Li, Z. Cai, Q. Wu, W.-Y. Lo, N. Zhang, L. X. Chen and $\mathrm{L}$. Yu, Rational design of porous conjugated polymers and roles of residual palladium for photocatalytic hydrogen production, J. Am. Chem. Soc., 2016, 138, 7681-7686.

51 H. P. Liang, A. Acharjya, D. A. Anito, S. Vogl, T.-X. Wang, A. Thomas and B.-H. Han, Rhenium-metalated polypyridine-based porous polycarbazoles for visible-light $\mathrm{CO}_{2}$ photoreduction, ACS Catal., 2019, 9, 3959-3968.

52 B. C. Ma, S. Ghasimi, K. Landfester, F. Vilela and K. A. I. Zhang, Conjugated microporous polymer nanoparticles with enhanced dispersibility and water compatibility for photocatalytic applications, J. Mater. Chem. A, 2015, 3, 16064-16071.

53 R. S. Sprick, B. Bonillo, M. Sachs, R. Clowes, J. R. Durrant, D. J. Adamsa and A. I. Cooper, Extended conjugated microporous polymers for photocatalytic hydrogen evolution from water, Chem. Commun., 2016, 52, 10008-10011.

54 P. F. Wei, M. Z. Qi, Z. P. Wang, S. Y. Ding, W. Yu, Q. Liu, L. K. Wang, H. Z. Wang, W. K. An and W. Wang, Benzoxazolelinked ultrastable covalent organic frameworks for photocatalysis, J. Am. Chem. Soc., 2018, 140, 4623-4631.

55 R. R. Liang, R. Han A, S. Q. Xu, Q. Y. Qi and X. Zhao, Fabricating organic nanotubes through selective disassembly of two-dimensional covalent organic frameworks, J. Am. Chem. Soc., 2020, 142, 70-74.

56 H. M. El-Kaderi, J. R. Hunt, J. L. Mendoza-Cortés, A. P. Côté, R. E. Taylor, M. O'Keeffe and O. M. Yaghi, Designed synthesis of $3 \mathrm{D}$ covalent organic frameworks, Science, 2007, 316, 268-272.

57 T. Ben, H. Ren, S. Ma, D. Cao, J. Lan, X. Jing, W. Wang, J. Xu, F. Deng, J. M. Simmons, S. Qiu and G. Zhu, Targeted synthesis of a porous aromatic framework with high stability and exceptionally high surface area, Angew. Chem., Int. Ed., 2009, 48, 9457-9460.

58 J. Huang and S. Richard Turner, Hypercrosslinked Polymers: A Review, Polym. Rev., 2018, 58, 1-41.

59 Z. Wei, Q. Chen and H. Liu, Hydroxyl modified hypercrosslinked polymers: targeting high efficient adsorption separation towards aniline, New J. Chem., 2021, 45, 11607-11617.
60 M. Errahali, G. Gatti, L. Tei, G. Paul, G. Rolla, L. Canti, A. Fraccarollo, M. Cossi, A. Comotti, P. Sozzani and L. Marchese, Microporous Hyper-crosslinked Aromatic Polymers Designed for Methane and Carbon Dioxide Adsorption, J. Phys. Chem. C, 2014, 118, 28699-28710.

61 Y. Zhang, L. Zhang, X. Zhang, D. Yang, C. Du, L. Wan, C. Au, J. Chen and M. Xie, Pyridine-based hypercrosslinked polymers as support materials for palladium photocatalysts and their application in Suzuki-Miyaura coupling reactions, New J. Chem., 2020, 44, 15202-15208.

62 L. Tan and B. Tan, Hypercrosslinked porous polymer materials: Design, synthesis, and applications, Chem. Soc. Rev., 2017, 46, 3322-3356.

63 N. Fontanals, R. M. Marce, F. Borrull and P. A. G. Cormack, Hypercrosslinked materials: preparation, characterisation and applications, Polym. Chem., 2015, 6, 7231-7244.

64 V. Davankov, V. Rogozhin and M. Tsjurupa, US Pat., 3729457, 1973.

65 Y. Gu, S. U. Son, T. Li and B. Tan, Low-Cost Hypercrosslinked Polymers by Direct Knitting Strategy for Catalytic Applications, Adv. Funct. Mater., 2021, 31, 2008265.

66 Z. Qian, Z. J. Wang and K. A. I. Zhang, Covalent Triazine Frameworks as Emerging Heterogeneous Photocatalysts, Chem. Mater., 2021, 33, 1909-1926.

67 P. Puthiaraj, Y. R. Lee, S. Zhang and W. S. Ahn, TriazineBased Covalent Organic Polymers: Design, Synthesis and Applications in Heterogeneous Catalysis, J. Mater. Chem. A, 2016, 4, 16288-16311.

68 M. Liu, K. Jiang, X. Ding, S. Wang, C. Zhang, J. Liu, Z. Zhan, G. Cheng, B. Li, H. Chen, S. Jin and B. Tan, Controlling Monomer Feeding Rate to Achieve Highly Crystalline Covalent Triazine Frameworks, Adv. Mater., 2019, 31, 1807865.

69 M. Liu, Q. Huang, S. Wang, Z. Li, B. Li, S. Jin and B. Tan, Crystalline Covalent Triazine Frameworks by In Situ Oxidation of Alcohols to Aldehyde Monomers, Angew. Chem., Int. Ed., 2018, 57, 11968-11972.

70 X. Jiang, P. Wang and J. Zhao, 2D Covalent Triazine Framework: A New Class of Organic Photocatalyst for Water Splitting, J. Mater. Chem. A, 2015, 3, 7750-7758.

71 J. Li, P. Liu, H. Huang, Y. Li, Y. Tang, D. Mei and C. Zhong, Metal-Free 2D/2D Black Phosphorus and Covalent Triazine Framework Heterostructure for $\mathrm{CO}_{2}$ Photoreduction, ACS Sustainable Chem. Eng., 2020, 8, 5175-5183.

72 C. Xu, Q. Xie, W. Zhang, S. Xiong, C. Pan, J. Tang and G. Yu, A Vinylene-Bridged Conjugated Covalent Triazine Polymer as a Visible-Light-Active Photocatalyst for Degradation of Methylene Blue, Macromol. Rapid Commun., 2020, 41, 2000006.

73 P. Katekomol, J. Roeser, M. Bojdys, J. Weber and A. Thomas, Covalent Triazine Frameworks Prepared from 1,3,5-Tricyanobenzene, Chem. Mater., 2013, 25, 1542-1548.

74 M. J. Bojdys, J. Jeromenok, A. Thomas and M. Antonietti, Rational Extension of the Family of Layered, Covalent, Triazine-Based Frameworks with Regular Porosity, $A d v$. Mater., 2010, 22, 2202-2205. 
75 P. Kuhn, A. Thomas and M. Antonietti, Toward Tailorable Porous Organic Polymer Networks: A High-Temperature Dynamic Polymerization Scheme Based on Aromatic Nitriles, Macromolecules, 2009, 42, 319-326.

76 W. Zhang, C. Li, Y. P. Yuan, L. G. Qiu, A. J. Xie, Y. H. Shen and J. F. Zhu, Highly Energy- and Time-Efficient Synthesis of Porous Triazine-Based Framework: MicrowaveEnhanced Ionothermal Polymerization and Hydrogen Uptake, J. Mater. Chem., 2010, 20, 6413-6415.

77 J. Xie, S. A. Shevlin, Q. Ruan, S. J. A. Moniz, Y. Liu, X. Liu, Y. Li, C. C. Lau, Z. X. Guo and J. Tang, J. Efficient Visible Light-Driven Water Oxidation and Proton Reduction by an Ordered Covalent Triazine-Based Framework, Energy Environ. Sci., 2018, 11, 1617-1624.

78 J. Liu, W. Zan, K. Li, Y. Yang, F. Bu and Y. Xu, Solution Synthesis of Semiconducting Two-Dimensional Polymer via Trimerization of Carbonitrile, J. Am. Chem. Soc., 2017, 139, 11666-11669.

79 S. Luo, Z. Zeng, H. Wang, W. Xiong, B. Song, C. Zhou, A. Duan, X. Tan, Q. He, G. Zeng, Z. Liu and R. Xiao, Recent progress in conjugated microporous polymers for clean energy: Synthesis, modification, computer simulations, and applications, Prog. Polym. Sci., 2021, 115, 101374.

80 X. Sheng, H. Shi, L. Yanga, P. Shao, K. Yu and X. Luo, Rationally designed conjugated microporous polymers for contaminants adsorption, Sci. Total Environ., 2021, 750, 141683.

81 Y. He, Z. Cheng, H. Zuo, C. Yan and Y. Liao, Green synthesis of pyridyl conjugated microporous polymers as precursors for porous carbon microspheres for efficient electrochemical energy storage, ChemElectroChem, 2020, 7, 959-966.

82 N. Chaoui, M. Trunk, R. Dawson, J. Schmidt and A. Thomas, Trends and challenges for microporous polymers, Chem. Soc. Rev., 2017, 46, 3302-3321.

83 J. Chen, W. Yan, E. J. Townsend, J. Feng, L. Pan, V. D. A. Hernandez and C. F. J. Faul, Tunable surface area, porosity, and function in conjugated microporous polymers, Angew. Chem., Int. Ed., 2019, 58, 11715-11719.

84 S. Luo, Z. Zeng, G. Zeng, Z. Liu, R. Xiao, P. Xu, H. Wang, D. Huang, Y. Liu, B. Shao, Q. Liang, D. Wang, Q. He, L. Qin and $\mathrm{Y} . \mathrm{Fu}$, Recent advances in conjugated microporous polymers for photocatalysis: designs, applications, and prospects, J. Mater. Chem. A, 2020, 8, 6434-6470.

85 A. Schneemann, R. Dong, F. Schwotzer, H. Zhong, I. Senkovska, X. Feng and S. Kaskel, 2D framework materials for energy applications, Chem. Sci., 2021, 12, 1600-1619.

86 V. Singh and H. R. Byon, Advances in electrochemical energy storage with covalent organic frameworks, Mater. Adv., 2021, 2, 3188-3212.

87 H. Vardhan, A. Nafady, A. M. Al-Enizi and S. Ma, Pore surface engineering of covalent organic frameworks: structural diversity and applications, Nanoscale, 2019, 11, 21679-21708.

88 X. Zhao, P. Pachfule and A. Thomas, Covalent organic frameworks (COFs) for electrochemical applications, Chem. Soc. Rev., 2021, 50, 6871-6913.
89 M. S. Lohse and T. Bein, Covalent Organic Frameworks: Structures, Synthesis, and Applications, Adv. Funct. Mater., 2018, 28, 1705553.

90 C. Wu, Y. Liu, H. Liu, C. Duan, Q. Pan, J. Zhu, F. Hu, X. Ma, T. Jiu, Z. Li and Y. Zhao, Highly Conjugated ThreeDimensional Covalent Organic Frameworks Based on Spirobifluorene for Perovskite Solar Cell Enhancement, J. Am. Chem. Soc., 2018, 140, 10016-10024.

91 X. J. Zhao, P. Pachfule, S. Li, T. Langenhahn, M. Y. Ye, C. Schlesiger, S. Praetz, J. Schmidt and A. Thomas, Macro/ Microporous Covalent Organic Frameworks for Efficient Electrocatalysis, J. Am. Chem. Soc., 2019, 141, 6623-6630.

92 X. Wang, M. Bahri, Z. Fu, M. A. Little, L. Liu, H. Niu, N. D. Browning, S. Y. Chong, L. Chen, J. W. Ward and A. I. Cooper, A Cubic 3D Covalent Organic Framework with nbo Topology, J. Am. Chem. Soc., 2021, 143, 15011-15016.

93 H. R. Abuzeid, A. F. M. EL-Mahdy and S. W. Kuo, Covalent organic frameworks: Design principles, synthetic strategies, and diverse applications, Giant, 2021, 6, 100054.

94 H. L. Nguyen and A. Alzamly, Covalent Organic Frameworks as Emerging Platforms for $\mathrm{CO}_{2}$ Photoreduction, ACS Catal., 2021, 11, 9809-9824.

95 Y. Zhang, J. Duan, D. Ma, P. Li, S. Li, H. Li, J. Zhou, X. Ma, $\mathrm{X}$. Feng and B. Wang, Three-Dimensional Anionic Cyclodextrin- Based Covalent Organic Frameworks, Angew. Chem., Int. Ed., 2017, 56, 16313-16317.

96 B. Zhang, H. Mao, R. Matheu, J. A. Reimer, S. A. Alshmimri, S. Alshihri and O. M. Yaghi, Reticular Synthesis of Multinary Covalent Organic Frameworks, J. Am. Chem. Soc., 2019, 141, 11420-11424.

97 A. Abid, S. Razzaque, I. Hussain and B. Tan, Eco-Friendly Phosphorus and Nitrogen-Rich Inorganic-Organic Hybrid Hypercross-linked Porous Polymers via a Low-Cost Strategy, Macromolecules, 2021, 54(12), 5848-5855.

98 Y. Cui, Z. Xu, H. Y. Li, D. J. Young, Z. G. Ren and H. X. Li, Synthesis of a Pyrazole-Based Microporous Organic Polymer for High-Performance $\mathrm{CO}_{2}$ Capture and Alkyne Carboxylation, ACS Appl. Polym. Mater., 2020, 2, 4512-4520.

99 B. Zhang, J. Yan, G. Lia and Z. Wang, Cost-effective preparation of microporous polymers from formamide derivatives and adsorption of $\mathrm{CO}_{2}$ under dry and humid conditions, Polym. Chem., 2019, 10, 3371-3379.

100 Y. Liu, S. Wang, X. Meng, Y. Ye, X. Song and Z. Liang, Increasing the surface area and $\mathrm{CO}_{2}$ uptake of conjugated microporous polymers via a post-knitting method, Mater. Chem. Front., 2021, 5, 5319-5327.

101 S. Mukherjee, M. Das, A. Manna, R. Krishna and S. Das, Newly designed 1,2,3-triazole functionalized covalent triazine frameworks with exceptionally high uptake capacity for both $\mathrm{CO}_{2}$ and $\mathrm{H}_{2}$, J. Mater. Chem. A, 2019, 7, 1055-1068.

102 H. R. Abuzeid, A. F. M. EL-Mahdy and S. W. Kuo, Hydrogen bonding induces dual porous types with microporous and mesoporous covalent organic frameworks based on bicarbazole units, Microporous Mesoporous Mater., 2020, 300, 110151.

103 A. F. M. El-Mahdy, C. Young, J. Kim, J. You, Y. Yamauchi and S. W. Kuo, Hollow Microspherical and Microtubular 
[3+3] Carbazole-Based Covalent Organic Frameworks and Their Gas and Energy Storage Applications, ACS Appl. Mater. Interfaces, 2019, 11, 9343-9354.

104 A. F. M. EL-Mahdy, C. H. Kuo, A. Alshehri, C. Young, Y. Yamauchi, J. Kim and S. W. Kuo, Strategic design of triphenylamine- and triphenyltriazine-based two-dimensional covalent organic frameworks for $\mathrm{CO}_{2}$ uptake and energy storage, J. Mater. Chem. A, 2018, 6, 19532-19541.

105 A. F. M. EL-Mahdy, Y. H. Hung, T. H. Mansoure, H. H. Yu, Y. S. Hsu, K. C. W. Wu and S. W. Kuo, Synthesis of $[3+3] \beta$ ketoenamine-tethered covalent organic frameworks (COFs) for high-performance supercapacitance and $\mathrm{CO}_{2}$ storage, J. Taiwan Inst. Chem. Eng., 2019, 103, 199-208.

106 R. Jagt, A. Vasileiadis, H. Veldhuizen, P. Shao, X. Feng, S. Ganapathy, N. C. Habisreutinger, M. A. van der Veen, C. Wang, M. Wagemaker, S. van der Zwaag and A. Nagai, Synthesis and Structure-Property Relationships of Polyimide Covalent Organic Frameworks for Carbon Dioxide Capture and (Aqueous) Sodium-Ion Batteries, Chem. Mater., 2021, 33, 818-833.

107 M. G. Mohamed, T. C. Chen and S. W. Kuo, Solid-State Chemical Transformations to Enhance Gas Capture in Benzoxazine-Linked Conjugated Microporous Polymers, Macromolecules, 2021, 54, 5866-5877.

108 Y. Zhang, D. Yi, P. Tu, S. Yang, Q. Xie, Z. Gao, S. Wu and $\mathrm{G}$. Yu, Boosting radioactive iodine capture of microporous polymers through strengthened host-guest interaction, Microporous Mesoporous Mater., 2021, 321, 111148.

109 M. G. Mohamed, M. Y. Tsai, C. F. Wang, C. F. Huang, M. Danko, L. Dai, T. Chen and S. W. Kuo, Multifunctional Polyhedral Oligomeric Silsesquioxane (POSS) Based Hybrid Porous Materials for $\mathrm{CO}_{2}$ Uptake and Iodine Adsorption, Polymers, 2021, 13, 221.

110 N. Baig, S. Shetty, S. Al-Mousawi and B. Alameddine, Conjugated microporous polymers using a copper-catalyzed [4+2] cyclobenzannulation reaction: promising materials for iodine and dye adsorption, Polym. Chem., 2021, 12, 2282-2292.

111 Y. Zhang, X. Hong, X. M. Cao, X. Q. Huang, B. Hu, S. Y. Ding and H. Lin, Functional Porous Organic Polymers with Conjugated Triaryl Triazine as the Core for Superfast Adsorption Removal of Organic Dyes, ACS Appl. Mater. Interfaces, 2021, 13, 6359-6366.

112 A. Hassan, A. Alam, M. Ansari and N. Das, Hydroxy functionalized triptycene based covalent organic polymers for ultra-high radioactive iodine uptake, Chem. Eng. Sci., 2022, 427, 130950.

113 A. F. M. EL-Mahdy, M. B. Zakaria, H. X. Wang, T. Chen, Y. Yamauchi and S. W. Kuo, Heteroporous bifluorenylidene-based covalent organic frameworks displaying exceptional dye adsorption behavior and high energy storage, J. Mater. Chem. A, 2020, 8, 25148-25155.

114 M. G. Mohamed, A. F. M. EL-Mahdy, Y. Takashi and S. W. Kuo, Ultrastable conductive microporous covalent triazine frameworks based on pyrene moieties provide high-performance $\mathrm{CO}_{2}$ uptake and supercapacitance, New J. Chem., 2020, 44, 8241-8253.
115 M. G. Mohamed, A. F. M. EL-Mahdy, M. M. M. Ahmed and S. W. Kuo, Directly Synthesized Microporous BicarbazoleBased Covalent Triazine Frameworks for HighPerformance Energy Storage and Carbon Dioxide Uptake, ChemPlusChem, 2019, 84, 1767-1774.

116 M. G. Mohamed, M. M. M. Ahmed, W. T. Du and S. W. Kuo, Meso/Microporous Carbons from Conjugated Hyper-Crosslinked Polymers Based on Tetraphenylethene for High-Performance $\mathrm{CO}_{2}$ Capture and Supercapacitor, Molecules, 2021, 26, 738.

117 M. G. Mohamed, X. Zhang, T. H. Mansoure, A. F. M. ElMahdy, C. F. Huang, M. Danko, Z. Xin and S. W. Kuo, Hypercrosslinked porous organic polymers based on tetraphenylanthraquinone for $\mathrm{CO}_{2}$ uptake and highperformance supercapacitor, Polymer, 2020, 205, 122857.

118 M. G. Mohamed, A. F. M. EL-Mahdy, T. S. Meng, M. M. Samy and S. W. Kuo, Multifunctional Hypercrosslinked Porous Organic Polymers Based on Tetraphenylethene and Triphenylamine Derivatives for HighPerformance Dye Adsorption and Supercapacitor, Polymers, 2020, 12, 2426.

119 A. F. M. EL-Mahdy, M. G. Mohamed, T. H. Mansoure, H. H. Yu, T. Chen and S. W. Kuo, Ultrastable tetraphenyl-pphenylenediamine-based covalent organic frameworks as platforms for high-performance electrochemical supercapacitors, Chem. Commun., 2019, 55, 14890-14893.

120 A. F. M. EL-Mahdy, Y. H. Hung, T. H. Mansoure, H. H. Yu, T. Chen and S. W. Kuo, A Hollow Microtubular Triazine-and Benzobisoxazole-Based Covalent Organic Framework Presenting Sponge-Like Shells That Functions as a High-Performance Supercapacitor, Chem. - Asian J., 2019, 14, 1429-1435.

121 M. M. Samy, M. G. Mohamed, A. F. M. El-Mahdy, T. H. Mansoure, K. C. W. Wu and S. W. Kuo, HighPerformance Supercapacitor Electrodes Prepared From Dispersions of Tetrabenzonaphthalene-Based Conjugated Microporous Polymers and Carbon Nanotubes, ACS Appl. Mater. Interfaces, 2021, 13, 51906-51916.

122 M. M. Samy, M. G. Mohamed and S. W. Kuo, Pyrenefunctionalized tetraphenylethylene polybenzoxazine for dispersing single-walled carbon nanotubes and energy storage, Compos. Sci. Technol., 2020, 119, 108360.

123 M. G. Mohamed and S. W. Kuo, Functional Silica and Carbon Nanocomposites Based on Polybenzoxazines, Macromol. Chem. Phys., 2019, 220, 1800306.

124 M. G. Mohamed, K. C. Hsu and S. W. Kuo, Bifunctional polybenzoxazine nanocomposites containing photocrosslinkable coumarin units and pyrene units capable of dispersing single-walled carbon nanotubes, Polym. Chem., 2015, 6, 2423-2433.

125 C. W. Huang, M. G. Mohamed, C. Y. Zhu and S. W. Kuo, Functional Supramolecular Polypeptides Involving $\pi-\pi$ Stacking and Strong Hydrogen-Bonding Interactions: A Conformation Study toward Carbon Nanotubes (CNTs) Dispersion, Macromolecules, 2016, 49(15), 5374-5385.

126 S. Kandambeth, J. Jia, H. Wu, V. S. Kale, P. T. Parvatkar, J. C. Jóźwiak, S. Zhou, X. Xu, Z. O. Ameur, E. A. Hamad, 
A. H. Emwas, O. Shekhah, H. N. Alshareef and M. Eddaoudi, Covalent Organic Frameworks as Negative Electrodes for High-Performance Asymmetric Supercapacitors, Adv. Energy Mater., 2020, 10, 2001673.

127 H. Wang, Z. Li, Z. Meng, X. Guo, Y. Du and H. Yang, An easily obtained hypercrosslinked pyrene-based porous organic polymer as a high-performance electrode material for lithium-ion batteries, New J. Chem., 2021, 45, 7060-7064.

128 Z. Wei, D. Wang, Y. Liu, X. Guo, Y. Zhu, Z. Meng, Z. Q. Yu and W. Y. Wong, Ferrocene-based hyperbranched polymers: a synthetic strategy for shape control and applications as electroactive materials and precursor-derived magnetic ceramics, J. Mater. Chem. C, 2020, 8, 10774-10780.

129 B. Y. Lu, Z. Q. Wang, F. Z. Cui, J. Y. Li, X. H. Han, Q. Y. Qi, D. L. Ma, G. F. Jiang, X. X. Zeng and X. Zhao, A Covalent Organic Framework with Extended $\pi$-Conjugated Building Units as a Highly Efficient Recipient for Lithium-Sulfur Batteries, ACS Appl. Mater. Interfaces, 2020, 12, 34990-34998.

130 Z. Li, J. Zhang, X. Jing, J. Dong, H. Liu, H. Lv, Y. Chi and C. $\mathrm{Hu}, \mathrm{A}$ polyoxometalate@covalent triazine framework as a robust electrocatalyst for selective benzyl alcohol oxidation coupled with hydrogen production, J. Mater. Chem. A, 2021, 9, 6152-6159.

131 H. S. Jena, C. Krishnaraj, S. Parwaiz, F. Lecoeuvre, J. Schmidt, D. Pradhan and P. V. D. Voort, Illustrating the Role of Quaternary-N of BINOL Covalent TriazineBased Frameworks in Oxygen Reduction and Hydrogen Evolution Reactions, ACS Appl. Mater. Interfaces, 2020, 12, 44689-44699.

132 A. F. M. EL-Mahdy, A. M. Elewa, S. W. Huang, H. H. Chou and S. W. Kuo, Dual-function fluorescent covalent organic frameworks: $\mathrm{HCl}$ sensing and photocatalytic $\mathrm{H}_{2}$ evolution from water, Adv. Opt. Mater., 2020, 8, 2000641.

133 Y. Chen, D. Yang, B. Shi, W. Dai, H. Ren, K. An, Z. Zhou, Z. Zhao, W. Wang and Z. Jiang, In situ construction of hydrazone-linked COF-based core-shell hetero-frameworks for enhanced photocatalytic hydrogen evolution, J. Mater. Chem. A, 2020, 8, 7724-7732.

134 T. Zhou, X. Huang, Z. Mi, Y. Zhu, R. Wang, C. Wanga and J. Guo, Multivariate covalent organic frameworks boosting photocatalytic hydrogen evolution, Polym. Chem., 2021, 12, 3250-3256.

135 D. Sengottuvelu, V. Kachwal, P. Raichure, T. Raghav and I. R. Laska, Aggregation-Induced Enhanced Emission (AIEE)-Active Conjugated Mesoporous Oligomers (CMOs) with Improved Quantum Yield and Low-Cost Detection of a Trace Amount of Nitroaromatic Explosives, ACS Appl. Mater. Interfaces, 2020, 12, 31875-31886.

136 Y. Tang, H. Huang, B. Peng, Y. Chang, Y. Li and C. Zhong, A thiadiazole-based covalent triazine framework nanosheet for highly selective and sensitive primary aromatic amine detection among various amines, J. Mater. Chem. A, 2020, 8, 16542-16550.

137 L. R. Ahmed, A. F. M. EL-Mahdy, C. T. Pan and S. W. Kuo, A water-soluble copper-immobilized covalent organic framework functioning as an "OFF-ON" fluorescent sensor for amino acids, Mater. Adv., 2021, 2, 4617-4629.

138 A. F. M. El-Mahdy, M. Y. Lai and S. W. Kuo, A highly fluorescent covalent organic framework as a hydrogen chloride sensor: roles of Schiff base bonding and $\pi$-stacking, J. Mater. Chem. C, 2020, 8, 9520-9528.

139 Z. Chen, K. Wang, X. Hu, P. Shi, Z. Guo and H. Zhan, Novel One-Dimensional Covalent Organic Framework as a $\mathrm{H}^{+}$ Fluorescent Sensor in Acidic Aqueous Solution, ACS Appl. Mater. Interfaces, 2021, 13, 1145-1151.

140 M. Faheem, S. Aziz, X. Jing, T. Ma, J. Du, F. Sun, Y. Tian and G. Zhu, Dual luminescent covalent organic frameworks for nitro-explosive detection, J. Mater. Chem. A, 2019, 7, 27148-27155.

141 M. G. Mohamed, N. Y. Liu, A. F. M. EL-Mahdy and S. W. Kuo, Ultrastable luminescent hybrid microporous polymers based on polyhedral oligomeric silsesquioxane for $\mathrm{CO}_{2}$ uptake and metal ion sensing, Microporous Mesoporous Mater., 2021, 311, 110695.

142 M. G. Mohamed and S. W. Kuo, Functional Polyimide/ Polyhedral Oligomeric Silsesquioxane Nanocomposites, Polymers, 2019, 11, 26.

143 M. G. Mohamed and S. W. Kuo, Polybenzoxazine/Polyhedral Oligomeric Silsesquioxane (POSS) Nanocomposites, Polymers, 2016, 8, 225.

144 M. G. Mohamed, T. H. Mansoure, Y. Takashi, M. M. Samy, T. Chen and S. W. Kuo, Ultrastable porous organic/inorganic polymers based on polyhedral oligomeric silsesquioxane (POSS) hybrids exhibiting high performance for thermal property and energy storage, Microporous Mesoporous Mater., 2021, 328, 111505.

145 W. Gong, X. Deng, K. Dong, L. Liu and G. Ning, A boranilbased conjugated microporous polymer for efficient visible-light-driven heterogeneous photocatalysis, Polym. Chem., 2021, 12, 3153-3159.

146 T. Chen, W. Zhang, B. Li, W. Huang, C. Lin, Y. Wu, S. Chen and H. Ma, Adsorptive Separation of Aromatic Compounds from Alkanes by $\pi-\pi$ Interactions in a Carbazole-Based Conjugated Microporous Polymer, ACS Appl. Mater. Interfaces, 2020, 12, 56385-56392.

147 B. Chen, L. Chen, Z. Yan, J. Kang, S. Chen, Y. Jin, L. Ma, H. Yan and C. Xia, Conjugated microporous polymers as a visible light driven platform for photo-redox conversion of biomass derived chemicals, Green Chem., 2021, 23, 3607-3611.

148 X. Jiang, K. Zhang, Y. Huang, B. Xu, X. Xu, J. Zhang, Z. Liu, Y. Wang, Y. Pan, S. Bian, Q. Chen, X. Wu and G. Zhang, Conjugated Microporous Polymer with $\mathrm{C} \equiv \mathrm{C}$ and $\mathrm{C}-\mathrm{F}$ Bonds: Achieving Remarkable Stability and Super Anhydrous Proton Conductivity, ACS Appl. Mater. Interfaces, 2021, 13, 15536-15541.

149 Y. Wang, H. Liu, Q. Pan, N. Ding, C. Yang, Z. Zhang, C. Jia, Z. Li, J. Liu and Y. Zhao, Construction of Thiazolo[5,4d] thiazole-based Two-Dimensional Network for Efficient Photocatalytic $\mathrm{CO}_{2}$ Reduction, ACS Appl. Mater. Interfaces, 2020, 12, 46483-46489. 
150 H. Xu, X. Li, H. Hao, X. Dong, W. Sheng and X. Lang, designing fluorene-based conjugated microporous polymers for blue light-driven photocatalytic selective oxidation of amines with oxygen, Appl. Catal., B, 2021, 285, 119796.

151 M. Xu, T. Wang, L. Zhou and D. Hua, Fluorescent conjugated mesoporous polymers with $N, N$-diethylpropylamine for the efficient capture and real-time detection of volatile iodine, J. Mater. Chem. A, 2020, 8, 1966-1974.

152 A. Singh, P. Verma, S. Laha, D. Samanta, S. Roy and T. K. Maji, Photochromic Conjugated Microporous Polymer Manifesting Bio-Inspired pcFRET and Logic Gate Functioning, ACS Appl. Mater. Interfaces, 2020, 12, 20991-20997.

153 Y. M. Li, L. Yang, L. Sun, L. Ma, W. Q. Deng and Z. Li, Chemical fixation of carbon dioxide catalyzed via covalent triazine frameworks as metal free heterogeneous catalysts without a cocatalyst, J. Mater. Chem. A, 2019, 7, 26071-26076.

154 Z. Shang, B. Zhao, Z. Wu, Y. Ding and A. Hu, Synthesis of Conjugated Mesoporous Hyper-cross-linked Polymers for Efficient Capture of Dibenzothiophene and Iodine, ACS Appl. Mater. Interfaces, 2020, 12, 56454-56461.

155 Z. Lu, X. Fu, H. Yang, Y. Zhao, L. Xiao and L. Hou, A covalent organic framework as a photocatalyst for atom transfer radical polymerization under white light irradiation, Polym. Chem., 2021, 12, 183-188.

156 W. Chen, Z. Yang, Z. Xie, Y. Li, X. Yu, F. Lu and L. Chen, Benzothiadiazole functionalized D-A type covalent organic frameworks for effective photocatalytic reduction of aqueous chromium(vi), J. Mater. Chem. A, 2019, 7, 998-1004.

157 L. Zhai, S. Yang, X. Yang, W. Ye, J. Wang, W. Chen, Y. Guo, L. Mi and Z. Wu, Constantinos Soutis, Qing $\mathrm{Xu}$ and Zheng Jiang, Conjugated Covalent Organic Frameworks as Platinum Nanoparticle Supports for Catalyzing the Oxygen Reduction Reaction, Chem. Mater., 2020, 32, 9747-9752.

$158 \mathrm{X} . \mathrm{Xu}, \mathrm{S}$. Wang, Y. Yue and N. Huang, Semiconductive Porphyrin-Based Covalent Organic Frameworks for Sensitive Near-Infrared Detection, ACS Appl. Mater. Interfaces, 2020, 12, 37427-37434.

159 M. G. Mohamed, C. C. Lee, A. F. M. EL-Mahdy, J. Lüder, M. H. Yu, Z. Li, Z. Zhu, C. C. Chueh and S. W. Kuo, Exploitation of two-dimensional conjugated covalent organic frameworks based on tetraphenylethylene with bicarbazole and pyrene units and applications in perovskite solar cells, J. Mater. Chem. A, 2020, 8, 11448-11459. 